Illinois State University

ISU ReD: Research and eData

Theses and Dissertations

7-1-2014

\title{
A Comparative Study Of The Practitioner's Role To Integrate Technology Within An Inquiry-Based Learning Environment
}

Ashley C. Mayor

Illinois State University, mayor.ashley@gmail.com

Follow this and additional works at: https://ir.library.illinoisstate.edu/etd

Part of the Curriculum and Instruction Commons, and the Educational Methods Commons

\section{Recommended Citation}

Mayor, Ashley C., "A Comparative Study Of The Practitioner's Role To Integrate Technology Within An Inquiry-Based Learning Environment" (2014). Theses and Dissertations. 284.

https://ir.library.illinoisstate.edu/etd/284

This Thesis is brought to you for free and open access by ISU ReD: Research and eData. It has been accepted for inclusion in Theses and Dissertations by an authorized administrator of ISU ReD: Research and eData. For more information, please contact ISUReD@ilstu.edu. 


\title{
A COMPARATIVE STUDY OF THE PRACTITIONERS' ROLE TO INTEGRATE TECHNOLOGY WITHIN AN INQUIRY-BASED LEARNING ENVIRONMENT
}

\begin{abstract}
Ashley C. Mayor
110 Pages

May 2015

This thesis considers alternative pedagogical approaches where the integration of technology is applied, determining if inquiry-based learning is an approach that can facilitate the integration process more effectively. The role of the practitioner was evaluated to determine beliefs, concerns, and perceptions of technology integration. Practitioners' use of an inquiry-based learning approach was gauged and compared with practitioners' use of a more traditional approach. The level of technology integration was assessed and compared as subgroups according to their teaching practices. The study analyzed the responses of teachers' survey data, with intentions to draw conclusions about the optimal approach for which to integrate technology.
\end{abstract}

This research study found that (1) the level of concern over technology integration is neither significant for the inquiry-based teachers nor the traditional teachers, (2) a significant difference occurred over the perceived use of technology for inquiry-based teachers in relation to traditional teachers, and (3) the level of perceived ability to integrate technology is neither significant with inquiry-based teachers nor traditional teachers. 
By analyzing the practitioner's beliefs, concerns, and perceptions about integrating technology, a comparison of one alternative pedagogical approach to a traditional teaching method was conducted. This research is intended to continue the discussion on pedagogical best-practices alongside technology integration, and aims to identify key perceptions of teachers when faced with the challenge of integrating technology in an authentic, meaningful, and engaging way. 


\section{A COMPARATIVE STUDY OF THE PRACTITIONER'S ROLE TO INTEGRATE TECHNOLOGY WITHIN AN INQUIRY-BASED \\ LEARNING ENVIRONMENT}

ASHLEY C. MAYOR

A Thesis Submitted in Partial

Fulfillment of the Requirements

for the Degree of

MASTER OF SCIENCE School of

Teaching and Learning ILLINOIS

STATE UNIVERSITY

2015 
A COMPARATIVE STUDY OF THE PRACTITIONER'S ROLE TO INTEGRATE TECHNOLOGY WITHIN AN INQUIRY-BASED

LEARNING ENVIRONMENT

ASHLEY C. MAYOR

COMMITTEE MEMBERS:

Steven Mertens, Chair

Barbara Meyer 


\section{ACKNOWLEDGMENTS}

First, I wish to thank Illinois State University for the teacher education preparation program providing my foundation on educational practice. Also, I thank the faculty and staff of the college of education for their dedication to inspiring students to pursue the democratic ideal while seeking to become leaders within their field.

I would like to thank the members of my committee, Dr. Steven Mertens and Dr. Barbara Meyer for their expertise and focus to support my efforts towards the development of my study. I am honored to have worked with this committee and have appreciated their thoughts and guidance. Also, I would like to thank Dr. Linda Haling for her wisdom and council.

Next, I would like to thank the participating schools that took part in this study. My experiences with each setting as a staff member helped to mold and shaped my practice. I learned so much from such wonderful, caring individuals, whom I admired daily for their abilities to establish a culture of learning.

Finally, I would like to thank my family for their never-ending encouragement; specifically, my mother, for her support, time, and prayers throughout this process. She has seen me grow as a learner, reaching goals beyond expectations. I am humbled to have had such valuable support.

A.C. M. 


\section{CONTENTS}

Page

ACKNOWLEDGMENTS $\quad$ i

CONTENTS $\quad$ ii

TABLES $\quad$ v

CHAPTER

I. INTRODUCTION 1

Significance 1

Area of Examination $\quad 5$

$\begin{array}{ll}\text { Problem Statement } & 6\end{array}$

II. LITERATURE REVIEW 8

Integration of Technology 9

Integration of Technology Embedded in the Process of Learning 11

Practitioners' Challenges to Integrate Technology 13

External factors that challenge technology integration $\quad 15$

Internal factors that challenge technology integration 16

Examining Practitioners' Beliefs over Technology Integration 20

Effective Pedagogical Practices $\quad 22$

Studies of Technology Integration within Inquiry-based Learning 26

$\begin{array}{ll}\text { Effectiveness } & 27\end{array}$

Challenges 28

Authentication 29

Case studies $\quad 29$

$\begin{array}{ll}\text { Summary } & 32\end{array}$ 
Research Questions

Hypotheses

III. RESESARCH METHODOLOGY 36

Research Design $\quad 36$

Setting $\quad 37$

Study Sample $\quad 40$

Recruitment Procedures $\quad 42$

Ethical Considerations 43

$\begin{array}{ll}\text { Instrumentation } & 45\end{array}$

Instrument Construction $\quad 45$

Validity and Reliability $\quad 53$

Data Collection Procedure $\quad 55$

Subgrouping Identification Procedure $\quad 56$

Statistical Measures $\quad 57$

Consideration of the Hypotheses Posed 61

IV. RESULTS 63

Subgroup Identification $\quad 63$

Findings and Results $\quad 65$

Research Question 1: Comparison of Level of Concern towards Technology Integration 65

Research Question 2: Comparison of Frequency of Use of Technology 67

Research Question 3: Comparison of Technology Integration Application $\quad 68$

$\begin{array}{ll}\text { Summary } & 70\end{array}$

V. DISCUSSION AND CONCLUSION 71

Theme 1: Pedagogical Practices and Concern over Integrating

Technology $\quad 72$

Theme 2: Use of Technology Does Not Indicate Integration 75

Theme 3: Orchestrating Learning 77

Limitations $\quad 80$

Conclusions $\quad 83$ 
$\begin{array}{ll}\text { APPENDIX A: Instrument } & 98\end{array}$

APPENDIX B: Script for School Administration: Request to Contact Teachers 105

APPENDIX C: Participant Recruitment 106

APPENDIX D: SEDL License Agreement 109 


\section{TABLES}

Table

1. Characteristics of teachers in the study sample

2. Data source of analysis

3. Demographics of study sample $\quad 64$

4. Descriptive analysis comparing stages of concern 66

5. Descriptive analysis comparing frequency of use 68

6. Descriptive analysis comparing technology integration application 


\section{CHAPTER I \\ INTRODUCTION}

\section{Significance}

Now that society has clearly passed the decade mark into the $21^{\text {st }}$ century, all of the students in our K-12 classrooms were born within the digital age, and are known as “digital natives" (Prensky, 2001). More so, the majority of students who are just beginning their academic careers are second generation digital natives. The digital age includes the present time and has been in existence since the use of digital medium, such as computers. These mediums have allowed for information to be transferred and accessed freely and quickly which, in turn, has created an automatic, knowledge-based society (digital age, 2011).

The digital age presents societal similarities to the industrial age of the $19^{\text {th }}$ century with a perpetual state of change and flux of innovation, yet an altered core of values. The values of the industrial age orbited around production and stamina to complete a framed skill-set role. These values, which equated to educational objectives, focused on the capacity of learning a task and performing it efficiently (Kliebard, 2004). In today's society, to be intellectually and economically competitive on a global scale requires a different skill set and disposition (Khan, 2012). The transformation of values and goals permeated both society and education through a gradual progression of change during the $20^{\text {th }}$ century, influenced by social, political, and economic changes, and the 
emergence of computer technology. The nuances of the $21^{\text {st }}$ century, such as instantaneous information access, global citizenship, and career fields that do not yet exist, for example; drone engineers, micro-grid specialists, or crypto-currency bankers, have presented a need for a new set of skills and literacies that enable an individual to be successful in their career and participate in society. The American Institutes for Research, AIR (2013) College and Career Readiness and Success Center conducted a meta-analysis to identify overall predictors of post-secondary success, concluding that 21 st century skills such as engagement in the learning process, social competencies, critical thinking, and informed decision making, are some key factors to success. The new intellectual necessities needed require a shift in curriculum and instruction in this digital age.

The digital age has increasingly invested in and relied on innovation and knowledge-based technologies as a shift from the mechanical production technologies of the industrial age. The field of education has been following suit with the state of change in the digital age, expecting learners to exercise innovative skills and literacies. To meet the demand to connect learners in their $21^{\text {st }}$ century classrooms, thus supporting investments have been made providing learners with access to technology. According to the Federal Communications Commission (FCC), 97\% of schools across the United States had internet connectivity as of 2010 (FCC, 2010). The FCC has recently announced plans to invest an additional $\$ 2$ billion dollars ( $\$ 4.4$ billion total) over the next two years to have a long term goal of $99 \%$ school connectivity (FCC, 2014). Building on this developing reality, an important matter of business includes how educational culture 
and instructional practice are actively making appropriate changes to best serve today's digital learners.

The number of stakeholders influencing the field of education has also grown, but teachers remain the fulcrum of the education process. As educators, "we are currently preparing students for jobs that don't yet exist... using technologies that haven't been invented...in order to solve problems we don't even know are problems yet" (Fisch, 2006). With this in mind, the focus in education is not on the technology itself but on the innovative skills necessary to leverage technology in purposeful ways.

With the growing importance of technology embedded in society, the United States has adopted technology literacy and application standards, for both students and teachers, to maintain. The National Educational Technology Standards for Students (NETS-S) (2007), now known as the ISTE Standards for Students (ISTE Standards•S), and the ISTE Standards for Teachers (ISTE Standards $\bullet$ ), formerly known as the National Educational Technology Standards for Teachers (NETS-T) (2008), were designed to establish a high level of technology proficiency. The International Society for Technology in Education (ISTE) is at the forefront of identifying the necessary skills, essential conditions, and performance indicators needed to be successful in the digital age. According to ISTE (2007), best practices for integrating technology into education focus on student learning that includes (1) creativity and innovation, (2) communication and collaboration, (3) research and information fluency, (4) critical thinking, problem solving, and decision making, (5) digital citizenship, and (6) competencies in technology operations and concepts. Likewise, the Partnership for $21^{\text {st }}$ Century Skills (2002) classified skills, the $21^{\text {st }}$ Century Skills (P21) Framework, that has been identified 
internationally as a necessity of a successful education, notably; learning and innovation skills, information, media and technology skills, and life and career skills (Bellanca \& Brandt, 2010; Eurydice, 2011; Morrison \& Lowther, 2010; Partnership for $21^{\text {st }}$ Century Skills, 2002; Saavedra \& Opfer, 2012).

The focus of long-term technology plans includes reconsidering how technology is used in the classroom, and how 21st Century Skills are taught. First considered is the presence of technology within the school setting. The United States, as well as the European Union, designed 2020 Educational Technology goals in 2010, utilizing a ten year outlook. The United States' plan, known as The National Education Technology Plan (NETP) (U.S. Department of Education (USDE), 2010), and the Key Data Report, developed a digital agenda establishing the Strategic Framework for Education and Training ('ET 2020') in the EU, both view their countries' access to information and communications technology (ICT) as an overall universal success (Eurydice, 2011). Both the United States and the European Union have turned their focus to policy, training, and support for the teacher's effective practice of these new technologies within the classroom. The NETP observed a gap in technology understanding that, "prevents technology from being used in ways that would improve instructional practices and learning outcomes" (p.10). The Key Data Report by the Education, Audiovisual, and Culture Executive Agency (EACEA) determined that, “....although ICT is included in regulations on teacher education, practical ICT-related pedagogical skills are rarely addressed at central level" (Eurydice, 2011, p. 14). Both the NETP and the Key Data Report outlook a future forecast for how education can be transformed by technology. 
As a result, government initiatives in the years to come are tasked those within the field to integrate technology in the classroom.

A continuing concern is not about having the digital resources, but instead it is about how to effectively maximize the use of digital resources available. At this point, lawmakers across the country have defined the "what" we are teaching, while teachers still remain responsible for determining the "how". Teachers rely on their training, experiences, personal beliefs, and existing educational research to support their decision making in pedagogical best practices (Marzano, 2010; Danielson, 2009). Aside from this issue, an additional concern is the considering exactly how teachers can integrate technology, according to the high standard detailed in the ISTE Standards and the $21^{\text {st }}$ Century Skills Framework. This then becomes the practitioners' challenge. Teachers are expected to integrate technology into their learning environment, often with minimal training, leadership, support, or overall school cultural shift to accommodate such integrations (ISTE, 2014; New Media Consortium, 2013; Sanchez, 2011; \& Sutton, 2011).

Pedagogical research has focused on, and will continue to focus on, the best means of preparing students for success in a future that educators cannot even fathom (Fisch, 2006), just like the $19^{\text {th }}$ century educators may not have imagined the digital-age or the globally connected classroom we have today. Changing practitioners' approaches to the education process and integrating technology as a means of transforming education are two of the most research-relevant methods being examined to meet students' needs (ChanLin, 2007; Wiesen, 2014). The integration of technology within the learning process redefines how to utilize technology as a necessary tool for learning, rather than as 
a subject to be learned. Educators play a pivotal role in this transformation of pedagogical practice that integrates technology as well as the endurance of technology in practice to realize the learning needs of digital natives.

\section{Area of Examination}

The purpose of this study focuses on the teacher's perspective on their role in the transforming educational landscape that integrates technology within learning, specifically examining pedagogical practice. Primarily of interest is the pedagogical approach utilized by teachers and their corresponding beliefs, concerns, and perceptions about integrating technology within teaching and learning. In contrast to a more traditional approach, the pedagogical approaches examined are of a constructivist and inquiry-based learning approach.

Inquiry-based learning is a pedagogical approach that is considered within this study for the potential to meet the needs of 21 st century learners, allowing technology to be integrated authentically within the classroom (an \& Dexter, 2003; Sutherland \& Joubert, 2009). The concept of teaching students how to learn, so that their processes can be applied to a wide-ranging scope of any future endeavor, has generated significant attention from educators looking to make learning more authentic (Morrison and Lowther, 2010; Sharples, Anastopoulou, \& Kerawalla 2012). The inquiry-based learning instructional strategy is designed to empower the learner with a personalized educational experience (Buckner \& Kim, 2013; Hakkarainen, Bollström-Huttunen, \& Hoffman, 2008; Morphew, 2012). For these reasons, inquiry-based learning was examined as a variable through the scope of educators' beliefs, and practice of, technology integration. 
This study examined the beliefs, concerns, and perceptions that practitioners have towards the integration of technology, in order to understand how teachers, using various pedagogical practices, may make decisions to integrate technology. The researcher made comparisons concentrating on the variable of the pedagogical approach. Practitioners utilizing traditional and inquiry-based learning methods explored their technology use and integration habits in an attempt to understand how teachers are best able to integrate technology within the learning process.

This Study Sought to:

1. Describe perceptions practitioners have towards technology integration within an inquiry-based setting.

2. Compare the perceptions of practitioners using inquiry-based pedagogical practices with practitioner perceptions using traditional practices.

3. Assess similarities and differences between practitioner perceptions using varied pedagogical approaches.

4. Recognize variations between groups of practitioners according to their pedagogical practice and their perception of technology integration.

5. Identify strengths and weaknesses of technology integration.

\section{Problem Statement}

Practitioners face many daily challenges while working to truly integrate technology within the learning process. These challenges include their preparation and support for changing practices, designing purposeful enriching experiences, their own beliefs and attitudes, and taking on a new role in the classroom. Far too often, the focus of study is on the technology tool itself, while the focus should be on the learning through 
integration of technology into the classroom in authentic and enriching ways (BrantleyDias \& Ertmer, 2013; Mishra \& Koehler, 2006; Morrison \& Lowther, 2010; Puentedura, 2013). Teachers' concerns over integrating technology can be an obstacle to effective technology integration (Ertmer, Ottenbreit-Leftwich, \& York, 2007; Holden \& Rada, 2011; Tondeur, Kershaw, Vanderlinde, \& van Braak, 2013). The method with which the practitioner attempts to implement practices of technology integration can impact the effectiveness of integration. Inquiry-based teaching is a method of education that has been identified as an alternative to traditional teaching. By examining the practitioners' primary pedagogical practices in correlation with their technological integration beliefs and habits, the researcher aims to identify characteristics of best practices in effective technology integration. 


\section{CHAPTER II}

\section{LITERATURE REVIEW}

The literature presented explores research conducted on practitioners' beliefs and concerns towards the integration of technology. Specifically, technology in this study will be synonymously referring to digital technology- encompassing all digital mediums such as computers, mobile devices, and computing devices with capacity to connect to the internet. The researcher reviewed literature concerning varying pedagogical practices, including an examination of the constructivist approach of inquiry-based learning, as an alternative to a more traditional teaching setting.

First, literature regarding the processes of integrating technology, including bestaccepted frameworks and understandings, along with the benefits and challenges are described. Then, currently identified practitioner concerns regarding technology integration are included. Next, the literature is considered for the effectiveness of pedagogical practices that enhance learning through technology integration. Then, the case is made for the practitioner's approach toward integrating technology through this practice as a less frequently utilized method of instruction, with a non-traditional practitioner role in the learning process. Finally, the research questions are presented along with the hypotheses explored within the present study. 


\section{Integration of Technology}

The definition of the integration of technology is presented in various ways throughout literature. Primarily, when considering the practice of integrating technology, the definition of this practice focused on the use of technology, as presented by the National Center for Education Statistics (NCES) (2002). According to NCES, technology integration is, "the incorporation of technology resources and technologybased practices into the daily routines, work, and management of schools" (2002, p. 75). As the practice of technology integration has evolved, a shift in focus occurred, and now is accepted through the lens of teaching and learning. The International Society for Technology in Education (ISTE), defines the true integration of technology within the National Educational Technology Standards (NETS) project, more recently known as the ISTE Standards for Teachers (ISTE Standards•T), including alignment with curriculum and instruction, active interaction with technology tools, and the use of technology to promote a range of important cognitive skills (ISTE, 2000, 2008, 2013). ISTE has led the movement on rebranding the field of educational technology by shifting the primary focus to research regarding pedagogical practices, rather than on any particular digital tool or device knowledge (Crompton, 2014; ISTE, 2012). A third consideration for understanding technology integration is made by a prominent educational technology researcher from Purdue University, Minchi Kim (2012). He defines technology integration as, "both the use of technology tools and the methods involved in determining optimal instructional practices" (p. 46). For the purposes of this study, the definition of technology integration is the practice of leveraging technology for the purposes of enhancing the learning process (ISTE, 2012; Kim, 2012). 
The definition of technology integration is conceptualized through the Technology Pedagogical Content Knowledge (TPACK) framework. The development of Technological Pedagogical Content Knowledge, also known as TPACK by Mishra and Koehler (2006; 2009), determined a new level of knowledge necessary for teachers to successfully integrate technology. The TPACK framework is a trinity of technological knowledge, pedagogical knowledge, and content knowledge, where expertise and application of the three cohesively are optimal. TPACK is one of the most accepted and studied frameworks of effective technology integration designed around knowledge domains, connections, and interactions between these domains (Brantley-Dias \& Ertmer, 2013; Koehler \& Mishra, 2009; Mishra \& Koehler, 2006; Voogt, Fisser, Roblin, Tondeur, and van Braak, 2013; Young, Young, \& Hamilton, 2013). The shift of focus to best practices within pedagogy to leverage the enhancements technology offers is emphasized in the most popular studies of application of the TPACK framework and the ISTE Standards. Brantley-Dias and Ertmer (2013) present a concern over TPACK through the concept of the Goldilocks Principle, where some knowledge domains in reality appear too small while others seem too large. This is true to the design of the framework as well as the research surrounding it. With the imbalance of the three framework domains in mind, the researchers call for further focus and study on the "just right" practice of the unifying TPACK convergence. This unique knowledge trifecta is a necessity for teachers to integrate technology effectively into learning and merits application understanding (Archambault \& Barnett, 2010; Brantley-Dias \& Ertmer, 2013; Bull, 2009; Mishra \& Koehler, 2006). 
Integration of Technology Embedded in the Process of Learning

Researchers have long considered the role that technology plays in the learning process. The three-decade-old "Delivery Truck Debate", between Clark $(1983,1994)$ and Kozma (1994), evaluates the influence of media versus the method of learning. The difference between these two recurrently regarded stances is the role technology plays within the education process as the most important element of successful learning versus a tool or medium that is utilized within learning, but not the determinant of learning. Clark (1983) concluded within his meta-analysis that, "there are no learning benefits to be gained from employing any specific medium to deliver instruction" and that it, "was not the medium that caused the change but rather a curricular reform that accompanied the change" (p. 445). This stance is still presented when considering research conducted primarily around the focus of best practices in teaching, rather than technology as a solution to the challenges within the education process (Lowther \& Morrison, 1998; Mellon, 1999; Hsu, Ho, Tsai, Hwang, Chu, Wang, \& Chen, 2012; Sappy \& Relf, 2010). The challenge then, is to consider the practitioner's role in the delivery truck debate. Sappy \& Relf (2010) reconsidered this debate and concluded that, "pedagogy has never been independent of a technology, but has been formed through the affordancespotentials and limitations- of the technologies used" (p. 2). This presents the argument that technology is a part of the learning process, and research should move beyond the consideration of technology as an "add-on" (Koehler \& Mishra, 2009; Morrison \& Lowther, 2010; Puentedura, 2013).

While many considered the purpose of technology in the learning process, others considered theories in learning with technology. Niederhauser (2013) defined two 
overarching theoretical perspectives of technology integration as learning from technology and learning with technology. These two camps echo the Clark and Kozma debate; regarding the difference that technology will have on teaching and learning. In alignment with the practice of integrating technology, the practice includes leveraging technology in various ways as described by Taylor (1980). Taylor (1980) named three particular orientations of computer use: tool, tutor, and tutee. When utilizing technology as a tool, the technology can "enhance the cognitive powers of human beings during thinking, problem solving and learning" (Niederhauser, 2013, p. 250). Learning from technology is evident in the orientation as a tutor when knowledge is transferred from a computer program, drill and practice activity, or guided practice interaction (Holzweiss, 2014; Sharples, et al., 2012). Learning with technology is evident when technology is oriented as a tutee, with learners as the programmers more deeply focused on the process of learning, utilizing computational thinking and drawing on richer understandings (Niederhauser, 2013). This concept of technology orientation as a tutee requires instruction focused on the process of learning, a crosscutting pedagogical understanding.

Several researchers have concluded the importance of integration into the learning process in such a way that students have authentic use of technology, not one in which technology is used as an overlay or additional subject to be studied (Goodyear \& Retalis, 2010; Morrison \& Lowther, 2010; Niederhauser, 2006; Stewart \& Schifter, 2010). Originally conducting research on the integration of technology within the area of mathematics, researchers Ozel, Yetkiner, and Capraro (2008) concluded a more holistic approach is necessary that “ $\ldots$ an effective implementation of technology augments the learning of every student by providing diversity in instructional models, developing a 
student-centered learning environment, and restructuring the teaching and learning process to make it more intellectually rigorous" (p. 82). The redesign of the learning environment, as described by Ozel et al. (2008), requires practitioners to make decisions on modes of executing the integration process.

The literature exposes different perspectives on the role technology plays in the classroom, the purpose for technology integration, and effective methods of implementation. The integration of technology is conceptualized as a part of the learning process, but still debate occurs over the credit due to the technology or modification in instructional practices for enhancing student learning. Practitioners are tasked with the responsibility of integrating technology and their select method and role can present in a variety of ways. Finally, the literature explored particular implementation practices that have been deemed effective means of true integration, yet the challenges practitioners face are also necessary to consider.

Practitioners' Challenges to Integrate Technology

Various researchers and organizations have set out to identify the specific challenges practitioners face when charged with the expectation to integrate technology. The European Network of Excellence established a research consortium named STELLAR, bringing together researchers from the educational sciences, the learning sciences, and computer science (Eurydice, 2011). This group of researchers was tasked to develop a strategic direction for technology enhanced learning (TEL). In order to do so, three 'grand challenge' themes for the practitioner were identified: "connecting learners, orchestrating learning and contextualizing learning" (Sutherland, Eagle, \& Joubert, 2012, p. 10). Second, The Horizon Report, published annually by the New 
Media Consortium (NMC) (2013), a well-revered forecast of the educational technology field, identified six challenges that exist when considering the integration of emerging technologies. These six challenges include (1) ongoing professional development not being valued and integrated into the culture of schools, (2) education's own practices limiting the uptake of new technologies, (3) new models of education competing with traditional models, (4) K-12 needing to address increased blending of formal and informal learning, (5) the demand for personalized learning not being supported by current technology or practices, and (6) not using digital media for formative assessment the way we should (NMC, 2013, p. 9). Third, Hew and Brush (2006) conducted an overview of literature from 1995-2006 to identify themes in studies relating to barriers of technology integration. This study defined technology integration as the use of computing devices for instructional purposes across the K-12 education field. Hew and Brush's six themes included resources, practitioner knowledge and skills, the institution culture, practitioner attitudes and beliefs, assessment, and subject culture (2006, p.226). A fourth study of internal barriers to technology integration focused primarily on the teacher practitioners' motivation to integrate technology within their classroom. Tondeur, Kershaw, Vanderlinde, and van Braak (2013) conducted a study specific to system factors influencing the success of technology integration. In this simulated recall study, the researchers identified three factors of influence including personal, pedagogical, and organizational factors, which make up the "black box" of technology integration (p. 435). The sample population in this study was unique to teachers who were already proficient in using technology. The findings of this study indicated that an interplay exists between influences and there are a set of critical characteristics that 
teachers need to possess for successful integration. These critical characteristics include; the teacher's innovativeness, their computer experience, and beliefs about education. Overall, these four expansive studies present the various themes or barriers that can be categorized according to the locus of barrier, external verses internal barriers (BrantleyDias \& Ertmer, 2013; Ertmer \& Ottenbreit-Leftwich, 2010; Sutherland, et al., 2012). Throughout these foundational studies, it is clear that the teacher practitioners' internal barriers have a significant effect on the integration practice. For the purposes of this study external and internal factors are examined separately, though they often occur simultaneously.

External factors that challenge technology integration.

Practitioners have identified resources, school and class culture, policies, time, and professional development as external factors that are barriers to integrating technology. Originally, the most prominent challenge teachers faced was to identify and utilize available resources. ChanLin's (2007) study on teacher perception found that "from the environmental aspect, teachers who were concerned more about support and management of resources...were likely to manage these resources" (p. 52). As mentioned in the introduction, the FCC (2014) investment in devices and connectivity over the next two years towards a goal of 99 percent would most likely eradicate the top concern of resources for practitioners.

Looking at a larger picture of schools that are now connected, the school culture, or environment was identified as an external barrier to effective integration (Hew \& Brush, 2006; Inan \& Lowther, 2010). In a teacher survey, Sanchez (2011) reported that, "lack of professional development (68.4\%), lack of time, no time to try new things 
(68.4\%)", were the most significantly reported issues (p.98). Professional development and teacher preparation programs have been identified as external factors that are barriers to teacher's ability to integrate technology (Inan \& Lowther, 2009; Sutton, 2011; Young, Young, \& Hamilton, 2013). According to a report published by the American Association of Colleges for Teacher Education (AACTE), "teacher preparation programs are rising to the challenge of infusing technology into course work. Some 98 percent of preparation programs prepare their students to use technology to deliver instruction, and 62 percent have a technology-related requirement for graduation or program completion" (2013, p.3). Therefore, the argument for lacking professional development as a barrier to applying the professional training is questionable.

Internal factors that challenge technology integration.

While not as visible or easily measured, internal factors are critical to the understanding of integration technology barriers (Hew \& Brush, 2006; Littleton \& Kerawalla, 2012). Within the last six years, research in the area of internal barriers' effect on technology integration has become a more prominent area of research (Fives \& Gill, 2015; Voogt, et al., 2013). Throughout the findings of these studies, a synthesis of five overall themes were identified; including a practitioners' knowledge and skills, selfefficacy, interest in integration, attitudes, and beliefs toward technology integration.

The most quantifiable researched internal factors are practitioners' knowledge and skills. Researchers Koehler and Mishra (2009; 2006) have identified that inadequacies of technology integration have been found to be a result of ill preparation of educators. Mishra and Koehler (2006) have stated, "these new technologies can disrupt the status quo, requiring teachers to reconfigure not just their understandings of technology but of 
all three components" in TPACK (Mishra \& Koehler, p. 1030). Koehler and Mishra (2009) identify that shortcomings or weaknesses by the practitioner in any of the three areas of TPACK affect the integration process. In their discussion, they call for further research to be conducted on the teacher or practitioner's ability to develop successfully in a marriage of all three areas. In the same year that TPACK was first designed, Roblyer (2006) presented the Technology Integration Planning (TIP) model. The present study's research observed that TPACK and TIP complement one another as TPACK provides the framework of knowledge and TIP supports teachers in determining the advantage, strategy, environment, objectives, assessments, and evaluation of integration on a fivephase cycle. This support model aids teachers in integrating technology effectively (Roblyer, 2006).

The internal factors of knowledge and skills are also considered by Puentedura (2013), who presents a linear model of the practitioners' challenges to reconfigure the learning process into four levels of integration, including substitution, augmentation, modification, and redefinition, known as the SAMR model. The SAMR model guides practitioners to question themselves, "Are you teaching above the line?" "The line" refers to the difference between the enhancement of learning with technology, "below the line", versus the transformation of learning with technology, "above the line". Transformative teaching is the true integration of technology (Mak, 2014). Puentedura's concept of transformational teaching includes technologies that modify and redefine the task, rather than enhancements that substitute or augment the task. SAMR allows the practitioner to consider the role technology plays within learning. There is a shift in how technology can be utilized as, "students are increasingly becoming sophisticated creators 
as well as consumers of digital media" (Bull, 2009, p.91). Kim's (2012) study concluded that, "many teachers find it difficult to interpret and transform their daily routines to incorporate new pedagogies to promote such skills" (p.46). Practitioner knowledge bases and skill sets, or lack thereof, impact their ability to integrate technology through the TPACK trifecta and at the highest level of transformation presented in SAMR.

Self-efficacy has been identified as a recurring internal barrier to technology integration (Brantley-Dias \& Ertmer, 2013; Hammonds, Matherson, Wilson, \& Wright, 2013; Holden \& Rada, 2011; Hsu, et al., 2012; Hsu, Wang, \& Runco, 2013). A practitioner's perception of their own ability to integrate technology, or confidence in their abilities, can be correlated to their usage of technology integration practices (Hsu, et al., 2012). The purpose of Hsu et al.'s (2013) study was to focus on integration frameworks that support scientific inquiry, as well as to investigate middle school teachers' confidence to practice digital literacies in science classrooms. The conclusions of this study determined that confidence was high in using technology, but meaningful technology integration and digital literacy practices were scarcely observed in the classroom setting. Hammonds, et al., (2013) identify a lack of self-efficacy as a cause for the absence of positive attitudes necessary to motivate teachers to integrate technology. Holden and Rada (2011), integrated self-efficacy into the framework of their version of the Technology Acceptance Model. Along with the belief that one can integrate technology well, researchers have also identified a need for teachers to be interested in or motivated, to integrate technology.

Interest in integration has been identified as a contributing factor for innovation progression (Ertmer, Ottenbreit-Leftwich, \& York, 2007; Hall, 2010; Hammonds, et al., 
2013; Kopcha, 2014; Tondeur et al., 2013). Tondeur et al.'s (2013) study of the "Black Box" of integration focused on the multifaceted influences teachers have in involving themselves in an innovation. The teachers studied were already pedagogically proficient at integrating technology and then influences, or barriers were studied. An interest in, or vision for, integration of technology was a critical characteristic identified. Kopcha (2014) names two layers of vision for or interest in technology integration as necessary, or if lacking, possible barriers to the integration process. These layers of vision come from within the practitioner, and also in a shared school or organizational vision for integration to happen. Hall (2010) identifies interest as a potential "Achilles Heel” to the integration of technology, determining that a practitioner who has a low level of personal interest will demonstrate this in their behavior of integration.

Attitudes that teachers feel toward the integration of technology weigh on their decision to implement the innovation. Researchers cite attitudes or dispositions towards integration as influential in measuring application of integration practices (Brantley-Dias \& Ertmer, 2013; Hammonds, et al., 2013; Hew \& Brush, 2006; Holden \& Rada, 2011, Hsu et al., 2012). Attitudes towards technology, towards their personal barriers, attitudes about integration practices and effectiveness, and towards usefulness and compatibility to student learners all impact a practitioners' election to integrate technology.

The most recurring and final barrier for teachers' integrating technology are their own beliefs (Brantley-Dias \& Ertmer, 2013; Hammonds, et al., 2013;Hew \& Brush, 2006; Holden \& Rada, 2011; Hsu, et al. 2012; Kopcha, 2014; Ottenbreit-Leftwich, Glazewski, Newby, \& Ertmer, 2010; Tondeur, et al., 2013). Beliefs in the context of the practitioner's value for technology integration, beliefs about pedagogical practice in 
regards to technology integration, beliefs in their ability to integrate, beliefs or perception of control over change practice to integrate effectively. For these reasons, beliefs are a primary focus of the present study and is explored further.

The internal factors practitioners are challenged with, in attempting to integrate technology, are considered by some researchers to be the most influential factors in identifying if teachers will develop the innovation (Hall, 2010). A practitioner's knowledge and skills built up through experiences, their self-efficacy, interest, attitudes, and beliefs are exposed as themes throughout the literature. The influence of a practitioner's beliefs and attitudes is explored further in this study. Examining Practitioners’ Beliefs over Technology Integration

While the definition of technology integration is clearly on the focus of best practices within teaching and learning, the literature explored in this section is focused on the practitioner's beliefs over the integration of technology. According to the International Handbook of Research on Teacher Beliefs, over 7,000 articles on teacher beliefs and technology were written between 1990 and 2012, and 65\% of those articles were written within the last six years (Fives \& Gill, 2015). It is clear through this content-analysis that practitioner beliefs, concerning teaching and learning in conjunction with technology, continue to gain momentum. Hew and Brush (2006) identified teachers' attitudes and beliefs as prominent barriers to technology integration practices. Ertmer, Ottenbreit-Leftwich, and York, (2007) identify inner drive and personal beliefs as the most influential integration barriers. Intrinsic factors were, "significantly more influential" when considering the use of technology. Ertmer et al. (2007) focuses on 
teacher perception and intrinsic factors, to determine if this fusion of inquiry and technology is an essential combination, which is revisited in this present study.

Brantley-Dias and Ertmer (2013) raise a concern in the research that teacher beliefs are a critical factor, but minimal consideration has been focused on beliefs when looking at TPACK framework of integration. In the comprehensive meta-analysis conducted by Voogt, et al. (2013) on studies of TPACK, only six of the 55 studies addressed how TPACK related to teacher beliefs concerning the integration of technology. Another concern is positive beliefs in their abilities may not necessarily translate to practices. This idea is evident in Fuchs and Akbar's (2013) teacher survey results, which reported that practitioners highly rate their personal technology proficiency at $70 \%$, but a mere $30 \%$ put their technological proficiencies to use within the classroom. A need for further examination of beliefs connection to practice is necessary.

Many researchers have concluded the importance of teacher's positive belief in a particular practice as a factor in determining effectiveness, as presented in the Technology Acceptance Model (TAM) (Davis, Bagozzi, \& Warshaw, 1989). Holden and Rada's (2011) study on the perceived ease of use and usability constructs over the practice of technology integration used the TAM model to measure self-efficacies. The findings of this study determined that, "perceived ease of use significantly influences perceived usefulness, and both perceived usefulness and ease of use significantly influence attitudes toward using or behavior intention to use" (p. 361).

Practitioners' beliefs over technology integration have become more prominent in research studies and presented as a significant influence to integrating technology (Brantley-Dias \& Ertmer, 2013; Hammonds, et al., 2013;Hew \& Brush, 2006; Holden \& 
Rada, 2011; Hsu, et al. 2012; Kopcha, 2014; Ottenbreit-Leftwich, et al., 2006; Tondeur, et al., 2013). Specifically impactful are the beliefs teachers have over technology integration as they connect to their pedagogical practices. The beliefs that teachers have about their abilities (self-efficacy), technology, and values as they relate to effective pedagogical practices, all impact their level of technology integration behavior.

\section{Effective Pedagogical Practices}

This section focuses on components of pedagogical practices that have been found in the literature to be conducive to the integration of technology. Practitioner selected pedagogical practices and the decision to integrate technology is the next set of literature reviewed. It is important to note, that while this researcher does acknowledge multiple-strategies and methods of instruction necessary to differentiate for all learners, for the purposes of this study, pedagogical practices or method approach, is considered separately.

The ISTE Standards identified necessary essential conditions and standards (conceptual skills and practices) by which teachers, should strive for, and maintain to promote the ultimate digital literacy learning environment (ISTE Standards $\bullet$ T, 2008). Technology integration models have emerged such as Technology-Based Learning (TBL), Technology Enhanced Learning (TEL) (Goodyear \& Retails, 2010) and TechnologyEnhanced Learning Environments (TELE), (Wang \& Hannafin, 2005), with promising results. Governmental funds and programming have continued to be allocated towards professional-development focused on technology integration in the ten-year outlook of the National Educational Technology Plan (2010), and so further study on the 
integration of technology within the context of learning is merited through best practice, as well as through national goals.

Innovations in education, such as the innovation to integrate technology, cannot be considered as a strict dichotomy but must be considered as a systemic progression of change (Fullan, 2011; Hall, 2010; Tondeur, et al., 2013). According to Fullan (2011) technology should not nominate a system reform, "wrong drivers alter structure, procedures, and other formal attributes of the system without reaching the internal substance of reform and that is why they fail" (p. 5). Fullan goes on to identify the right drivers, which work directly to effectively change the culture, including pedagogy. This theory of technology integration identifies the importance of pedagogical practice over technology tools as drivers of change. Hall (2010) identifies technology innovations as a process not an event, recommending a continuum of change be considered as a process of implementation rather than being thought of as an adoption. Tondeur et al. (2013) identified a system of factors and influences in the results of the study as a progression over time, 'the teachers' ongoing learning experiences rather than training affected the development of the quality of their practices" (Tondeur et al., 2013, p.445). As determined by Fullan (2011) and Tondeur et al. (2013) teachers' gradual progress towards integrating technology is effective due to systemic changes, specifically pedagogy.

The practitioner's role in establishing key components within the learning environment is significant. Schümmer and Lukosch (2007) determined that the "design of computer mediated interaction depends heavily on the human factor” (p. 65). Their case-study research concluded that designing computer supported-collaborative learning 
environments were necessary to the collaborative learning process. Along with a basis of collaboration within the learning environment, research best practices overwhelmingly support a student-centered learning environment (Danielson, 2009; ISTE, 2007; Marzano, 2010; Partnership for 21st Century Skills, 2011). For the purpose of this study, a studentcentered environment is a practice of students taking an active role in their learning process. The many benefits of student-centered learning come with great responsibilities of the learner (Hakkarainen, Bollström-Huttunen, \& Hoffman, 2008; Morrison \& Lowther, 2010). In order for the learning to be effective within such an environment, practices of reflection, organization, metacognition, and analysis must all be utilized by the learner (Bybee, 2014; International Baccalaureate Organization, 2014; White \& Frederiksen, 1998).

Further studies conclude that creative instructional methods are more effective and "...teachers who embrace creative teaching methods tend to have higher positive attitudes towards technology use in the classroom" (Holden \& Rada, 2011, p. 348-349). The Progressive Inquiry Project identified deeper engagement, student freedom to construct knowledge, and collaborative study, as benefits to integrating technology into their pedagogical approach tested (Viilo, Seitamaa-Hakkarainen, \& Hakkarainen, et al. 2012). These two studies identify collaborative learning and creative instructional methods as effective pedagogical practices in integrating technology.

While in its original design TPACK was not aligned with one specific pedagogical practice, researchers have worked to identify that some instructional approaches are more powerful than other approaches for preparing our students for the 21st century (Brantley-Dias \& Ertmer, 2013; Partnership for 21st Century Skills, 2011). 
Best practices in the integration of technology, just as studies of best practices, have been conducted in various areas within the field of education, and are then accepted within evaluation models, and integrated into teacher training programs, as ideal teaching methods (Danielson, 2009; Marzano, 2010). A meta-analysis of technology integration trends throughout research conducted between 2000 and 2009 found the greatest percentage of research focused on "Pedagogical Design and Theories" related to technology integration (Hsu, et al., 2012, p.359). These researchers predicted that, "more research will examine the effectiveness of these pedagogical models for different TBL contexts in the future" (Hsu, et al., 2012, p.367). The context of integrating technology is considered through the pedagogical practice employed.

In 2002, Chinn and Malhotra discussed the need for further study on instructional strategies that ensure authentic inquiry tasks, and called for research to examine inquiry that is "non-textbook" authentic, including authentic scientific reasoning, and verbal inquiry, simulated tasks. ChanLin (2007) found that teachers who embraced creative teaching methods tended to have higher positive attitudes towards technology use in the classroom. Reiterating earlier researchers, Hermans, Tondeur, van Braak, and Valcke (2008), confirm that teachers with more constructivist beliefs tend to use technology more frequently. Koh, Chai, and Tsai (2010) and Ertmer and Ottenbreit-Leftwich (2010) are consistent with the findings for teachers with constructivist beliefs and indicate that they use technology in more challenging ways. Overall, the consensus of these researchers is that authentic, constructive, and creative instructional practices are effective. 
As with all innovations in the field of education, it is important to consider the impact on learning and thus the pedagogical practices conducive to effective innovations. In the consideration of technology integration specifically, research has found a set of essential conditions (ISTE, 2008; Goodyear \& Retails, 2010; Wang \& Hannafin, 2005) that elicit cohesive integration. In addition to the learning environment, a studentcentered, creative, and collaborative culture of learning have all been deemed effective pedagogical practices, identifiably with technology integrated into the process (Hakkarainen, Bollström-Huttunen, \& Hoffman, 2008; Morrison \& Lowther, 2010; Viilo, Seitamaa-Hakkarainen, \& Hakkarainen, et al. 2012). The effective pedagogical practices identified build a case for further examination of a particular pedagogical approach specifically embracing the identified variables of practice to enhance the integration of technology.

Studies of Technology Integration within Inquiry-based Learning As identified in the previous section, best practices in learning currently being supported by research include student-centered collaboration, constructivist learning, critical thinking, and processing. Inquiry-based learning is a trending form of discovery learning, or open-learning, with roots in the constructivist model, and theories of John Dewey, that have again recently drawn attention as a method that is engaging, creative, and opens up opportunities for problem solving (Morrison \& Lowther, 2010; Papert, 1993; Schank, 2011). Inquiry-based learning has been found to empower students in become fully engaged and have more ownership within the process of their learning (Hakkarainen, Bollström-Huttunen, \& Hoffman, 2008; IBO, 2014; Savery, 2006; Weinberger, Stegmann \& Fischer, 2007). 
Inquiry learning has been evaluated in a variety of studies with most researchers defining inquiry in a similar manner, but presenting a spectrum of different representations of how inquiry is manifested (Alfieri, Brooks, Aldrich, \& Tenenbaum, 2011; Chinn \& Malhotra, 2002; Lowther \& Morrison, 2003; Savery, 2006). Many inquiry representation models have a variety of interpretations of what inquiry-based learning is and looks like. For the purposes of this study, inquiry will be defined as a process from which learners collaboratively begin wondering about a concept, topic, or idea, and pursue problem-solving activities, such as experimentation or data collection, to analyze and develop new knowledge, and finally reflect on the newfound knowledge. The purpose of this definition is for application opportunities that are non-specific to a particular content area and that are purely focused on the process of learning.

\section{Effectiveness.}

Multiple studies of effectiveness have reported that inquiry-based learning representations are only effective when a level of support is provided (Chinn \& Malhotra, 2002; Hickey \& Filsecker, 2012; Littleton \& Kerawalla, 2012; Scanlon, Anastopoulou, \& Kerawalla, 2012). Chinn and Malhotra (2002) determined that proper teacher preparation is needed to implement inquiry. Littleton and Kerawalla (2012) report that learners need support managing their inquiry in order to be effective. Scanlon et al. (2012) detail the orchestration of inquiry as a key to effectiveness. Orchestration gives an alternative analogy to the role of the teacher within the learning process, as the conductor of classroom. STELLAR uses the term 'orchestrating' to refer to, "the design and real-time management of learning situations, taking into account the learners, the role of the teacher or trainer, the role of assessment and the digital and non-digital tools used" 
(Sutherland, et al., 2012. p. 16). Rather than the commonly referenced "guide on the side", the teacher's role within inquiry is much more pivotal bringing a variety of pieces together, relying on improvisation, and understanding the learners' needs. It is important to consider the necessity for support within the inquiry process; this form of support or scaffolding is necessary for effective inquiry to take place. Thus, effectiveness is evident in inquiry-based learning, particularly when it is supported appropriately by a facilitator.

Challenges.

Studies challenge inquiry-based learning for, and blame deficiencies on, the difficulties teachers face implementing such a mode of learning. These difficulties have been identified as the teachers' abilities to achieve the level of improvisation necessary, significant competence on modeling the process, inquiry-guiding support questioning, shifting control to the learner, establishing a culture supportive to a collaborative community, (Edelson, Gordin, and Pea, 1999; Furtak, 2005; Lakkala, Lallimo, \& Hakkarainen, 2005; Savery, 2006; Viilo, Seitamaa-Hakkarainen, \& Hakkarainen, et al. 2012). Evaluating the role of the teacher within the inquiry process as an orchestrator, Littleton et al. (2012), indicated that orchestration is very difficult to achieve successfully because of the level of improvisation necessary, based on significant competence and inquiry-guided training. Research teams Kirschner, Sweller, and Clark (2006), as well as Alfieri, Brooks, Aldrich, and Tenenbaum (2011), conducted meta-analyses of prior studies, identifying critics of various discovery-learning practices, such as inquiry-based learning. Alfieri et al. (2011) reported that un-assisted discovery learning, as a form of inquiry, did not improve learning when compared to explicit instruction practices. Kirschner et al. (2006) were blunt in concluding that students may actually have a 
negative impact from inquiry with unguided learning practices as “...they may develop misconceptions or incomplete knowledge" (p. 35). These major critics lead future study to focus on the importance of the teachers' roles to support and guide the process.

\section{Authentication.}

The following studies suggested that technology integration could enhance the pedagogical practice of inquiry-based learning. Technology has been used as a tool to model real world situations that could not otherwise be simulated, as studied by van Joolngen, de Jong, Lazonder, Savelsbergh, and Manlove (2005). Scanlon (2012) considered that using open resources, or online data resources, offers a solution to the concern over the lack of quantity and variety of resources; with open resources, this possibility is magnified. Pea et al., (2012), explored the support that technology provides towards the learning process by offering new possibilities to, "capture, upload, and interactively analyse new datasets", which they identify as, "flexible architecture”, thus providing the organizational scaffolding allowing the learner to focus on, "the deployment of inquiry-based learning activities" (p.109). Crippen and Archambault (2012) identify the value technology can offer to inquiry through scaffolding inquiry instruction. Through these studies, the integration of technology was fluidly utilized to enhance the pedagogical practice of inquiry-based learning. However, now a case has been developed for the further study of inquiry-based learning.

Case Studies.

Various cases are considered as a sampling of studies specifically pertaining to the integration of technology through an inquiry-based pedagogical practice. The samples were included in the study for relevance of the focus on the pedagogy, the role of 
the practitioner, the population sample, and the setting utilized. The Personal Inquiry Project study (Littleton, Scanlon \& Sharples, 2012) determined the importance of making the learning, and specifically the inquiry, meaningful and personally relevant. The investigations that are pursued within inquiry further authenticate the learning process for the students, as they are a part of the development process. "Such activities also improve student understanding and retention of knowledge" (Wentworth \& Monroe, 2011, p. 265). Even some researchers who do not promote inquiry-based learning (Alfieri et al., 2011), appear to be in agreement over the effectiveness of student involvement and engagement with the implementation of inquiry-based learning.

Along with the Personal Inquiry Project, another inquiry-based learning design developed and examined at the University of Memphis, called the iNtegrating Technology for inQuiry model, or the NTeQ Model (Lowther \& Morrison, 1998; Lowther \& Morrison, 2003; Morrison \& Lowther, 2010), is worthy of exploration as it focuses on the integration of technology within the open-ended inquiry learning environment. The learning process focus within this design includes, "combining the use of computer technology as a tool with an emphasis on problem solving and reflection will result in increased student achievement” (Morrison \& Lowther, 2010, p.10). NTeQ is a pedagogical model, not a curriculum, which can be implemented by practitioners requiring a level of technological competency, as identified by TPACK in Mishra and Koehler (2006). NTeQ places practitioners in the role of orchestrator, as identified in Littleton et al. (2012). Limited external research has been conducted based on this model. 
Various international studies on the integration of technology found that inquirybased learning practices align with effective integration. Lakkala et al. (2005) study on the teacher's design of inquiry proved, "successful and significant", within primary school settings in which inquiry was implemented using integrated technology (p.18). The study identified the integration of technology into inquiry as a, "very versatile way for collective knowledge advancement, combining the use of multiple working spaces, threaded discourse areas, document sharing and commenting, and links to Web sources" (p.18). The Progressive Inquiry Model (Hakkarainen, 1998), developed by researchers at Helsinki University, presents an approach of discovery through technology. This model is significant for optimal integration of technology within inquiry. The Progressive Inquiry Model relies on the, "interrelated technical, social, epistemic, and cognitive support structures" (Hakkarainen, Bollström-Huttunen, \& Hoffman, 2008, p. 157) of inquiry and computer supported collaborative learning (CSCL) developed by Hakkarainen (1998). The teacher's role within CSCL meets the requirements identified in the literature as optimal to best practices in pedagogy. A case study (Viilo et al., 2012) using Progressive Inquiry within The Artefact Project analyzed the teacher's perceptions and reflections through a progressive diary over a three year period. The format of this case study in particular, considering the population, analysis of perception, and setting of this research are significant to the present study.

The constructivist practice of inquiry-based learning incorporates specific learning design characteristics that have impacted student learning (IBO, 2014; Littleton \& Kerawalla, 2012; Morrison \& Lowther, 2010; Scanlon et al., 2012). In addition to the pedagogical practice alone, case studies have detailed the integration of technology 
within inquiry-based learning practices to the benefit of student learning (Crippen \& Archambault, 2012; Littleton, Scanlon \& Sharples, 2012; Morrison \& Lowther, 2010). The challenges that teachers face in effective inquiry-based learning practices were also examined; including the difficulty for teachers to improvise instruction through "orchestration", changing the role they play in the classroom (Hickey \& Filsecker, 2012; Littleton, Scanlon \& Sharples, 2012; Pea, et al., 2012). Specific characteristics of inquiry-based instruction, such as a focus on the learning process, authentic, creative, and collaborative learning experiences, are described leveraging technology to enhance learning in ways that cannot be achieved alternatively. Primarily, the field of research conducted on integrating technology using inquiry-based learning, employs case-study methodology. There is a need for further consideration of the impacts of integrating technology through this pedagogical practice by alternative methods of research.

Summary

This literature presented the teachers' perspectives of technology integration within the context of pedagogical practice. Barriers to integrating technology, specifically internal barriers were identified in research findings, which merits this study's focus on teacher perceptions, concerns, attitudes, and beliefs towards the integration process. Alongside, the evaluation of practitioners' internal barriers, a study of pedagogical practices is a significant component of the perception study, to be explored.

Ertmer et al. (2007); Inan and Lowther (2009); Sanchez (2011); Sutherland, Eagle, and Joubert (2012), and others, all focus on teacher perception of the technology integration process. These studies identify specific concerns teachers have related to 
technology integration, but further study merits other factors influencing these teacher concerns, specifically the setting in which they are attempting technology integration. This study is influenced by the research to focus on teacher perception and intrinsic factors to determine if the pedagogical practice primarily implemented will be a variable to practitioners' concerns, beliefs, and perception of integrating technology.

This study will focus on the integration of technology comparing an inquiry-based learning context with a traditional learning environment, to identify themes of practitioner beliefs, concerns, and perception of technology integration across settings.

\section{Research Questions}

Research Question 1: Do differences occur between the beliefs/concerns of inquiry-based teachers and traditional teachers about integrating technology to enhance student learning?

Research Question 2: Do differences occur between the perceived use of technology of inquiry-based teachers and traditional teachers?

Research Question 3: Do differences occur between the perceived technology integration practices of inquiry-based teachers and traditional teachers?

Hypotheses

Teachers who have a more positive belief of their ability to integrate technology will be able to do so more successfully. Teachers who work in an inquiry-based learning setting will perceivably find more opportunities to integrate technology effectively into the design of inquiry due to the nature of the learning process. Inquiry-based learning will also benefit from the integration of technology due to the amount of data available for accessing, the quality of resources, and the tools available for organizing, analyzing, 
and reporting inquiry findings. Teachers working within a traditional setting will also find ways to integrate technology, but may report that the authenticity of the integration is more challenging.

The researcher considered alternative pedagogical practices where the integration of technology was applied to determine if inquiry-based learning is an approach that can facilitate the integration process more effectively. The role of the practitioner was evaluated to determine beliefs, concerns, and perceptions of technology integration. Practitioners using an inquiry-based learning approach were compared with practitioners within a traditional educational setting. The study analyzed responses of teachers' survey data, with intentions to draw conclusions about the optimal approach for which to integrate technology.

Research Question 1: Do differences occur between the beliefs/concerns of inquiry-based teachers and traditional teachers about integrating technology to enhance student learning?

Null Hypothesis: The level of concern over technology integration is neither significant for the inquiry-based teachers nor the traditional teachers.

Directional Hypothesis: The level of concern over technology integration with inquiry-based teachers would demonstrate a significant difference over the level of concern traditional teachers would experience.

Alternative Hypothesis: The level of concern over technology integration demonstrates a significant difference with the traditional teachers over the level of concern inquiry-based teachers would experience. 
Research Question 2: Do differences occur between the perceived use of technology of inquiry-based teachers and traditional teachers?

Null Hypothesis: No significant difference occurs between the perceived use of technology for neither inquiry-based teachers nor traditional teachers.

Directional Hypothesis: A significant difference occurred over the perceived use of technology for inquiry-based teachers, in relation to traditional teachers.

Alternative Hypothesis: A significant difference occurred over the perceived use of technology for traditional teachers, in relation to inquiry-based teachers Research Question 3: Do differences occur between the perceived technology integration practices of inquiry-based teachers and traditional teachers?

Null Hypothesis: The level of perceived ability to integrate technology is neither significant with inquiry-based teachers nor traditional teachers.

Directional Hypothesis: The level of perceived ability to integrate technology demonstrates a significant difference with inquiry-based learning teachers comparative to traditional teachers.

Alternative Hypothesis: The level of perceived ability to integrate technology demonstrates a significant difference with traditional teachers comparative to the inquirybased teachers. 


\section{CHAPTER III RESEARCH METHODOLOGY}

The purpose of this research was to identify a best-practices approach to pedagogy for effective technology integration within the learning process. In order to compare between pedagogical practice and technology integration, this study explored teacher perception of concern, use, and application, towards technology integration. The researcher targeted two different pedagogical practices, traditional and inquiry-based, to identify any possibility of differences between the sample populations toward the integration of technology.

\section{Research Design}

Research Question 1: Do differences occur between the beliefs/concerns of inquiry-based teachers and traditional teachers about integrating technology to enhance student learning? Research Question 2: Do differences occur between the perceived use of technology of inquiry-based teachers and traditional teachers?

Research Question 3: Do differences occur between the perceived technology integration practices of inquiry-based teachers and traditional teachers?

The researcher investigated the questions by completing a comparison of two populations of teacher practitioners, those using primarily traditional teaching practices, 
and those implementing primarily inquiry-learning practices. The researcher utilized a quantitative instrument to determine participants' placement into subgroups. The placement resulted from participant responses to instrument items that concerned their practices. Additionally, the researcher summated all responses per subgroup placement.

The researcher then identified relationships between the degree to which the subgroups integrated technology and their pedagogical practices. To address the first research question, the researcher conducted a review of each subgroup's level of concern towards the integration of technology, using the Stages of Concern Questionnaire (SoC) (George, Hall, \& Stiegelbauer, 2006). Next, the researcher sought to answer the second and third research questions by interpreting the responses of the two pedagogical practices subgroups to items that concerned their perceived ability to use technology within their instructional strategies as well as, with students, and their perceived technology application. The design of this research was exploratory and interpretive in nature. Participants were self-reporting their beliefs, concerns, and perceptions of their own abilities, and thus interpreting their own practice. When reviewing the results, response variability is plausible due to participants' individual perceptions and experiences reported.

\section{Setting}

The researcher selected two settings for the collection of data within this research study. These settings were chosen out of convenience and familiarity, as the researcher had been employed by both schools as a certified teacher. The two settings utilized within this study provided an inclusion of a diverse population of teacher practitioners. 
The first setting, designated in this study, was identified, as the international school. This setting utilizes inquiry-based learning practices, as defined by the mission of the school, as the primary method of learning (International School of Ulm/Neu-Ulm, 2011). The international school received authorization from the International Baccalaureate Organization (IBO) to offer the inquiry-based curriculum and reached accreditation status by 2013 (www.ibo.org). International Baccalaureate (IB) accreditation at the international school setting affirms the implementation of inquirybased teaching practices and inquiry-aligned curriculum. The international school is one of over 3,800 schools accredited by the IBO to implement their inquiry-learning program (www.ibo.org). The IBO first established their education foundation in 1968, beginning with a secondary level, diploma program, followed by a middle years program in 1994, and finally a primary years program in 1997, offering a complete inquiry-based international education for students ages 3 to 19 years old (www.ibo.org).

All of the international school teachers have completed specific International Baccalaureate curriculum programs training, hold certifications as IB teachers, and must complete continuing professional development according to inquiry-practices endorsed by the IBO. Teachers within this school are accountable for utilizing an inquiry-based method of teaching, according to their evaluation process at the building level, and the accreditation process at the international level. The researcher selected this setting because of its established practice of inquiry-based learning as the primary method of instruction across grade levels and disciplines.

The particular educational setting selected for this research was a school with a pre-kindergarten through grade 12 education program. The international school was 
established in Neu-Ulm in 2005, and has about 200 students with 27 teaching staff members (International School of Ulm/Neu-Ulm, 2011). The international school is located in the town of Neu-Ulm, in the region of Bavaria, in the south of Germany. According to the 2011 census, the population of this town was 52,706. The town of NeuUlm is one of Germany's rural districts (Statistisches Bundesamt Deutschland, 2011). Neu-Ulm's neighboring city, Ulm, has a population of 116,761 people, with a larger international population due to international companies and the Universität Ulm (Statistisches Bundesamt Deutschland, 2011). No information was available on the student population's socio-economic status, but this school is a private school funded through student-based tuition.

The second setting, designated in this study, was identified as the public school. The researcher selected this school as a means of comparison to the setting described previously. While it was not assumed within this study that the public school setting teacher participants do not, in fact, use an inquiry-based learning approach, the school's mission does not designate a specified method of learning as primary, nor have teachers employed by the institution been required to go through any specified training towards any particular instructional approach (Delavan CUSD \#703, 2014). The public school teachers received certification from the state to teach at their particular level and content area. All teachers within this public school must be highly qualified in the areas in which they teach according to state requirements. Teachers at this school are required to comply with a standards-based curriculum according to the state's recent adoption of the Common Core State Standards in 2010. Schools across the state were required to begin implementation of the standards during the 2013 - 2014 school year (Illinois State Board 
of Education, 2014). The Common Core State Standards pertain to the areas of English language arts and mathematics (National Governors Association \& Council of Chief State Officers, 2010).

The public school is located in Delavan, Illinois, in the United States of America. Delavan is a rural community with a population of 1,689 people (U.S. Department of Commerce, 2010). According to the National Center for Education Statistics (2012), Delavan's School District has 474 students and an 11.45 student/teacher ratio. The public school, like the international school, services students ages $3-18$, in a Pre- Kindergarten through grade 12 education program. Delavan's student population consists of 35.5\% low income (Illinois State Board of Education, 2013).

The researcher did not directly consider the demographics of the student body of either school selected within the study, as the focus of the research was primarily on teacher perceptions. There are a variety of similarities between the two settings, including the type of geographical community and level of educational services offered. Differences include size of student body, geographical location and educational practices defined.

\section{Study Sample}

All certified teachers from the selected schools were invited to participate in this study including 27 teachers from the international school and 41 teachers from the public school. A total of 33 teachers participated in the data collection, of which 13 participants were from the international school and 20 participants were from public school.

In order to utilize clean data within the study, the researcher decided to exclude two cases from the study. The first exclusion was from the international school, due to an 
incomplete consent form. The second exclusion made was also from the international school, due to incomplete instrument responses. Overall, the participants responded with a 93\% viable response rate, including 11 participants from the international school and 20 participants from the public school, for a total of 31 participants included in the study. Of the remaining 31 participants, $35.5 \%$ taught at the international school and $64.5 \%$ taught at the public school (Table 1). The study had a comprehensive response rate of $45.59 \%$ of the entire teaching populations at both settings. The researcher intended the original sample to include an equal number of participants from the two participating settings, but after further consideration of the research questions, the setting was not the primary determining variant, and a balance of settings was no longer required.

All 31 participants were current, certified educators employed full-time in the prekindergarten through grade 12 education field. At the time of recruitment, all of the participants possessed a bachelor's degree or higher level of education. The researcher used English to administer the research instrument and only accepted native English speakers in the study. The participants from the international school were all native English speaking, and were expatriates of native English speaking countries, specifically, Canada, Australia, the United States, South Africa, Ireland, and the United Kingdom. All those invited to participate in this study instructed medium sized classes, consisting of 10 -22 students. The participants did not report gender, age, race, ethnicity, or socioeconomic level demographics. The participants possessed a range of teaching experiences and taught in various grade levels, ranging from 1-30 years of experience (Table 1). None of the participants reported over 30 years of experience. Nearly half of the participants $(48.4 \%)$ have taught for 10 years or less. The level of current teaching 
position ranged from elementary to high school (Table 1). The majority of this study's participants taught at the elementary level (38.7\%).

Table 1

Characteristics of teachers in the study sample

\begin{tabular}{lcc}
\hline & Number & Percent \\
\hline Current teaching setting & & \\
& 11 & 35.5 \\
International school & 20 & 64.5 \\
Illinois public school & & \\
Years of experience & 9 & 29.0 \\
$1-5$ & 6 & 19.4 \\
$6-10$ & 3 & 10.7 \\
$11-15$ & 4 & 12.9 \\
$16-20$ & 8 & 25.8 \\
$21-25$ & 1 & 3.2 \\
$26-30$ & 0 & 0.0 \\
31 or more & & \\
Level of current teaching position & & \\
Elementary school & 12 & 38.7 \\
Middle school & 5 & 16.1 \\
High school & 9 & 29.0 \\
Multiple levels & 5 & 16.1 \\
& & \\
Type of classroom & & \\
Self-contained & 13 & 41.9 \\
Not self-contained & 18 & 58.1 \\
\hline
\end{tabular}

\section{Recruitment Procedures}

The recruitment process began by contacting school administrators that oversaw the two study sites. The researcher presented the administration at both the international school and the public school with the goals of the research, consent forms, and the 
measurement tool, (Appendix B). Prior to contacting practitioners or conducting any research at the chosen schools, the researcher completed proper protocol as requested by the schools' policies. The researcher identified these two settings out of convenience, as the researcher had worked as a part of the teaching staff with both schools used in the study. The researcher began individual participant recruitment once the administration gave consent at each school. The researcher made contacts for recruitment personally and electronically to individual teaching staff members. The researcher made personal contacts at the public school while, purely utilizing electronic contacts with the international school. A script for participant recruitment was developed (Appendix C). Next, the interested participants received a consent form, via hardcopy or electronic format, dependent on setting; all required a signed document returned to the researcher. The administration distributed the recruitment materials via email at the international school setting, as requested by the administration and approved by the institutional review board (IRB); alternatively the researcher distributed recruitment materials directly to participants in the public school setting.

\section{Ethical Considerations}

The participants experienced nominal psychological risks due to the nature of the study. Nevertheless, the researcher considered risks, which included breach of confidentiality among research participants who may have shared their responses or discussed the study with one another, as they are familiar with one another in the workplace. Another risk consideration included social risks. The participants experienced minimal social risks in this study regarding their profession and regarding

the opinion they offered to the value of the study. The researcher assured that the content 
of the instrument was not sensitive in nature, thus there was no effect on the participants' financial standing, employment, or reputation. The instrument did not cover any subject matter that was illegal or inappropriate in nature, so participants did not incriminate themselves. The administrators at each school setting consented to the study taking place within their school, but the researcher did not recruit administrators as participants in the study. School administrators had no influence over the individuals' choice to participate in the study and were not included in the collection of the instrument.

To avoid the potential social risks of individual participants, the researcher conducted the instrument anonymously to ensure no invasion of privacy took place. No direct identifiers were collected that would expose participant identity. Participants had the choice to complete as much, or as little of the instrument, as they wished to share. The researcher only accepted data collected with informed consent. The researcher informed participants of the purpose of the study prior to their choice to participate and the collective data that the researcher utilized in the study itself allowed for confidentiality between the individual responses and the reported data.

The researcher took measures to ensure confidentiality of the participants within the study. During the completion of the instrument, the researcher took measures to assure the participants' confidentiality by permitting them to complete the instrument untimed, in a location of their choosing. After the collection of data, the researcher maintained the confidentiality of participants by saving any electronic data on a password protected hard drive which the researcher had sole access. Also, the researcher took measures to secure any hardcopy data in a secure filing cabinet in a private residence that the researcher had sole access. 
In order to prevent any type of psychological risks within the group setting from occurring, individual participants had the right to complete the instrument on their own time in a setting of their choosing. The researcher did not collect data in a group format. The researcher utilized summative subsample data to minimize the risk to the individual participant, without directly analyzing individual data.

The conditions and time permitted to complete the instrument minimized social risks for the participants. All individuals recruited to participate in the study had experience in the field of consideration, and were in specific situations in which they practiced the method of instruction considered. Since individuals chose their own setting, in which to complete their instrument, the study caused no more than minimal social risk. The ethical considerations detailed were disclosed to the IRB and approved as a viable study.

Overall, the study sample included 31 participants across two different educational settings. Participants demographic details identified along with environment setting details provide an overview of the study sample. Finally, ethical considerations were taken at the forefront of this study to minimize risk for participants.

\section{Instrumentation}

\section{Instrument Construction}

The two components of the instrument utilized within the study included two parts: The Stages of Concern Questionnaire, and Evaluating the Use of Technology within Pedagogy (see Appendix A) (SEDL, 2013). Participants responded to the instrument focused on the areas of concern for technology integration, inquiry-based 
practices, technology use, and integration practices. The researcher used the instrument to gather information regarding each of the three research questions posed.

Part 1 of the instrument was used to assess participants' beliefs/concerns about integrating technology into the curriculum as an innovation. George, Hall, and Stiegelbauer (2006) originally developed and designed the SoC to measure seven identified stages of concern towards the implementation of a new area of innovation. The Southwest Educational Development Laboratory (2013) website states that, "the purpose of this questionnaire is to determine what people are thinking about when using various programs or practices. It is intended to assess their levels of concerns at various times during the adoption process" (http://www.sedl.org). The tool was used with the initial intent to determine the participant's level of concern over the integration of technology as an innovation within their practice.

For the purposes of this study, the Stages of Concern tool was used to indicate an overall practitioner level of concern. The initial intent of the tool was used to develop an individual Stages of Concern Profile, but a composite score of individuals, and thus groups can be used (George, Hall, \& Stiegelbauer, 2006). The SoC identifies seven unique stages of concern as awareness, informational, personal, management, consequence, collaboration, and refocusing. The questionnaire is comprised of a series of 35 questions, five questions per stage of concern regarding the innovation of integrating technology. The designers of the most recent SoC Questionnaire made improvements based on research conducted on the tool (George, Hall, \& Stiegelbauer, 2006). The Southwest Educational Department Laboratory (SEDL, 2013) granted copyright 
permission for the use of the most updated version of the SoC Questionnaire (2006) (Appendix D).

The area identified as the innovation for the $\mathrm{SoC}$ tool is the integration of technology into the curriculum, which is also the dependent variable of the current study. Participants rated their current beliefs/concerns regarding each of five prompts related to the seven stages of concern, for a total of 35 questions. Each participant reported their current level of concern as directed by the eight point Likert-type scale that ranged from 0 "irrelevant" to 7 "very true of me now." The participant considered only their current teaching position when reporting the level of concern within the implementation of the innovation. The higher the number indicated on the rating scale, the higher the level of concern the participant had about the particular prompt. Participants that reported rating of 0 , expressed a very low level of concern towards the innovation or the prompt, and were considered by the tool as non-users, having scant awareness level, or irrelevant concern of the innovation at that time (George, Hall, \& Stiegelbauer, 2006).

Alternatively, when participants reported a rating of 7 , the individual is expressed a very high level of concern about the innovation at that time. A sample of how to indicate responses utilizing this Likert-type scale rating was included in the instructions of this part of the instrument (Appendix A). Scoring of the SoC Questionnaire occurred by adding the responses to the five items, within each subset of the seven areas of concern. Each item within the set of five items had the possibility for the same eight point scale Likert-type rating with a range of 0 to 35 as possible raw scores. Then, the researcher calculated the raw scores within the areas of concern, and converted them to percentile scores for each of the seven stages of concern identified by the tool creators SEDL. 
The second part of the instrument solicits respondent opinions about their current practices of technology use and integration application. The researcher quantified the participants' perceived ability to use technology and integrate it into the curriculum in Part 2 of the instrument, (Appendix A). The researcher identified the importance of measuring both the participants' use of technology and application of true technology integration practices. The researcher designed Part 2 of the instrument for the specific purposes of this study. The instrument items included in Part 2 were essential to the primary purpose of identifying the research participants' level of inquiry-learning practices, for determining their use of technology, and application of technology integration practices. The researcher designed this portion of the instrument about the use of technology, in order to address the second research question posed. The researcher quantified responses and considered any existing relationships between integrating technology with the participants' perceived application of teaching practice. There are two sections included in Part 2 of the instrument, Evaluating the Use of Technology within Pedagogy: section (A) demographics, and section (B) pedagogical practices (see Appendix A).

Section A, of Part 2 of the instrument indicates a series of four demographical items to provide for opportunities of analyses considered. Demographic items requested the study participant to indicate current data on instructional setting, years of teaching experience, age of students currently taught, and the containment level of the setting. The instrument's demographic section consisted of items with quantitative measures. First, the researcher asked the participants to indicate their attained level of teaching experience, quantified in increments of five years, ranging from one year to over 30 years 
of experience. Based on demographical information available from the self-reported data on school websites, from the participating school sites, the researcher understood that a majority of the participants would indicate a level of experience within the first two ordinal categories of this demographic item. Further study on level of experience and relationships with ease to integrate technology, can be conducted by comparing teaching experience ordinals as independent variables.

Lastly, the researcher measured classroom setting by level of containment. Thirteen of 31 participants (41.9\%) reported teaching in a self-contained setting, and 18(58.1\%) taught in a non-self-contained setting (Table 1). After further consideration of the research questions, this data collected was not utilized in the analysis of the study.

Through Section B, of Part 2 of the instrument, the researcher solicited the response of the research participant to consider indicators of their current pedagogical practices. The researcher grouped similar items together in order to best answer each research question (items 5-7, 8-12, and 13-16). Categorical data was collect from each of these items individually according to established ordinal scales of measure. The collection of item types pertaining to each research question we combined for each participant's responses and identified as a composite score, to be interpreted by the researcher as interval data.

The researcher designed the specific examples posed in items 5 through 7 according to the ISTE Standards $\bullet$ (2008) and as indicators of inquiry-based learning. Participants indicated how often they used inquiry-based learning practices (item 5), how often they used technology within instructional strategies (item 6), and how often students used technology in tasks (item 7). For all three items, participants 
responded to a series of cases regarding their perceived use of technology, while utilizing inquiry-based learning practices according to a Likert-type scale rating system. Items 5 and 6 of the instrument, asked participants to select their level of use on a four-point scale, ranging from, "Almost Never" to "Frequently." Item 7 utilized the same four-point scale, but also provided the alternative of "Not Applicable" in the case that the participant may not utilize the practice mentioned.

The researcher formulated items 8 through 12 as application items, with consideration of the NTeQ model (Morrison \& Lowther, 2010), the Progressive Inquiry model (Hakkarainen, Bollström-Huttunen, \& Hoffman, 2008), and the TPACK model (Mishra \& Koehler, 2006). These items presented cases of application that measured levels of alignment of technology integration with inquiry-based learning practices. Item 8 represented a nominal indicator of the learning environment. Participants responding "yes" indicated that their environment was more student-centered with technology, aligning with an integrated approach. Participants responding with "no" indicated that their learning did not become more student-centered due to technology, supporting the null hypothesis. The researcher formatted item 9 as an ordinal indicator of the participants' level of integration of technology, as first considered by Taylor (1980), as a tool, tutor, or tutee. Participants who indicated a response of "tutee" aligned with the highest level of integration, transforming learning according to the SAMR model (Puentedura, 2013). Participants that reported their use of technology as a "tool" aligned to the simplest level of integration, according to the SAMR model. The researcher formatted item 10 to determine if the learning taking place was teacher-driven or student driven, with a response of student-driven indicating alignment with inquiry learning 
practices. Items 11 and 12 asked participants to consider the activity prior to the use of technology and during the use of technology. These two items also allowed for determinations of alignment with inquiry learning practices. According to the theory behind the NTeQ model, the more student-centered and student-driven the learning, the more ownership the learner has over why they will go to the technology, and thus would indicate a higher level of inquiry (Morrison \& Lowther, 2010). The participants' specified reason for using the technology was included as another indicator of a level of technology integration.

The researcher structured the instrument to offer responses that aligned with inquiry-based practices, and those that were not. Participants who selected use for research, communication or problem solving, were indicating a degree of inquiry-based learning practices taking place. Participants who selected uses of production and educational (drill and practice) indicated less use of inquiry-based learning practices. The researcher used items 11 and 12 as a comparison of consistent results concerning the subgrouping process detailed previously. The participant's responses in item 5 should demonstrate consistency throughout items 11 and 12. Assuming that all of the participants in this study do utilize technology within their learning environments; items 8 through 12 focused on how the use of technology was taking place.

To collect data intended to support analysis designed to answer research question three, items 13 through 16 were designed to help interpret participants' application of technology integration practices. The SAMR model (Puentedura, 2013) provided the basis for constructing a selection of responses across the integration spectrum posed in the model, using a categorical scale, ranking the level of technology integration from 
enhancing to transforming learning. Item response alternatives offered a series of four situational responses to the study participant. Each of the responses correlated to a level of the SAMR model; the first response for each item provided an example of technology used for substitution, the second response as an example of the augmentation, the third as an example of technology modifying the task, and the fourth as an example of how the technology redefined the learning task. When analyzed, the researcher considered the responses by calculating a composite score of the collection of items, in an effort to get measure of the participant's whole concept of integrating technology through the increasingly advancing degrees of integration presented by SAMR. Ratings of the higher levels, substitution and augmentation, were aligned more directly with the true nature of technology integration as measured by the composite score calculated. Overall, the researcher evaluated the participants' frequency of technology integration and frequency of the use of inquiry-learning practices, within Part 2 of the instrument and then compiled these results according to the subgrouping assigned, determined by practice subgroups. The researcher relied on Part 2 of the instrument in order to determine subgroups and to produce findings for research questions two and three. The researcher posed research questions two and three to identify if any relationships existed between participants' pedagogical practice and their frequency of use and technology integration practices.

The design of Part 2, Section B of the instrument included situational and example response items for the participant to select represented primarily as categorical data. Once the participant selected these situations or example responses, the researcher coded them according to the level of integration and inquiry practice they indicated was representative of their application. In order to do so, the researcher quantified the 
responses to items 13 - 16 in an ordinal scale according to the increasing levels of technology integration from the lowest level of substitution to the highest level, integrating technology to redefine the learning. The composite variable range could be from $4-16$ points. A lower score representing a lower level of integration practices. The higher the overall composite value on the four scenarios presented, the more the participant would apply integration practices. The researcher utilized these four items to analyze the participants' initial reactions to the true nature of integrating technology. Val idity and Reliability

The Research and Development Center for Teacher Education at the University of Texas at Austin developed Part 1 of the he Stages of Concern Questionnaire, (SoC) as a diagnostic tool (George, Hall, \& Stiegelbauer, 2006). As reported by Clark (2002), “extensive research has assured [SoC's] validity and reliability. Studies with the SoC Questionnaire have indicated that reliability of the instrument is satisfactory.” (p.34). Since the SoC update in 2006, validity studies conducted by SEDL have also determined the accuracy of the SoC Questionnaire (SEDL, 2013). According to the creators of the SoC, the new updates (2006) took into consideration the adjustment of a zero value versus a non-response. The internal reliability testing demonstrated an estimated reliability of .66, and within subgroups of the data, the alpha coefficients ranged from low to moderate, .57 to .75 . The reliability testing considered a range of elementary and secondary teachers, as well as university faculty members.

For the present study, the sample population range was more concentrated than in the sample population used in the reliability testing. By including a more closely related sample, including only elementary and secondary teachers, the alphas may be lower. 
The tool is appropriate for use with a sample population of educators as the language is appropriate to their professional vocabulary and understanding. The reliability of the tool was analyzed according each individual stage of concern with an overall range of correlation coefficients $(r=.13$ to $r=.54)$ (George, Hall, \& Stiegelbauer, 2006). The most recent reliability study also found that the sample was predominantly made of nonusers of the innovation, $88 \%$, this was including the new method of analysis with the Stage 0 scale utilized. The present study was also predominantly comprised of nonusers, and aligns with the reliability assessment of the tool's findings. Due to the typical occurrence of a nonuser rating, the entire profile, including fluctuation between each individual stage, needs consideration to identify characteristics that may indicate dissimilar results.

The second part of the instrument, Part 2: Evaluating the Use of Technology within Pedagogy, is a data collection tool that the researcher has not tested as an instrument for validity or reliability at the time of this study. Due to the nature of the sample, it was not practical to run a pilot. The researcher used a collection of data from this component of the instrument to support the development of future research in understanding best-practices of integrating technology. The models used in development of the items, such as the NTeQ model and the SAMR model, are two examples of the technology integration within inquiry-based learning models that exist.

The instrument designed for the purpose of this study was intended to measure the level concerns teacher practitioners have over integrating technology. Also, the research designed the instrument to identify current inquiry-based instructional practices with technology and mediums of student technology use, within the scope of inquiry-based 
practices to determine if difference occurs between perceived use of technology. Finally, the instrument design included technology-integration application practices, as a measure of the extent to integration perceived. The instrument was considered for validity and reliability according to the scale of this study. The instrument design limitations are disclosed in conjunction with the discussion of this study.

\section{Dat a Collection Procedure}

Individual participants from both settings selected for the study received identical instruments. The researcher administered the instrument in a paper/pencil format. The researcher assembled the instrument and distributed it to both settings: virtually, via email, for the international school, and in person for the public school. The reason for variation of tool distribution in the different sample groups was the researcher's location relative to the settings of each sample group. The original intended sample collection time was to be two months; however, the researcher extended the period another two months, totaling four months, due to unanticipated school closures and administrator response delays at the international school. Participants returned completed instruments through hardcopy or scanned and attached to an email format. The researcher deleted all emails after saving the attached files on a password-protected computer, only accessible by the researcher. Participants returned completed instruments and the researcher stored them in a secure location. The researcher input complete data of individual participants into the Statistical Package for the Social Sciences (SPSS) $\left(21^{\text {st }}\right.$ Ed.) database in order to conduct the statistical analysis of the study and provide results to determine conclusions. 


\section{Subgrouping Identification Procedure}

The researcher recruited participants from two different educational settings, but, for the purposes of this study, the researcher did not use the participants' setting as the sole determinant for placement in subgroups according to teaching practice. For the analysis of pedagogical practice in relationship to the integration of technology, the responses to items on the measurement tool were used to subgroup participants. This subgrouping, based on the participants' responses, aimed to alleviate biases that indicate setting determines practice. For the current study, the researcher did not make this assumption. The professionals' setting does not strictly indicate that they do or do not use inquiry practices. The researcher used this notion to prevent bias and considered all participants according to their perceived and self-reported practices. The researcher administered identical instruments to the teacher practitioners across both settings. Then, the participants returned the instruments, which the researcher analyzed according to the subgroup-established parameters detailed in the "Statistical Measures" section below. The researcher identified participants in subgroup 1 as traditional practice teachers, and participants in subgroup 2 as inquiry-based practice teachers.

First, the researcher conducted the analysis to establish the two categorized subgroups, identified as traditional teachers and inquiry teachers, according to the responses of the participants on their practice in the classroom (See Appendix A: Measurement Tool Part 2, item 5). These nine indicators of the instrument determined the participant's level of use of inquiry as they are representative to the inquiry process (Hakkarainen, Bollström-Huttunen, \& Hoffman, 2008; Morrison \& Lowther, 2010). The researcher summated the frequency of using inquiry-based learning practices to 
determine a case's level of inquiry as on an ordinal scale assigning values of $1-4$, with a possible composite score ranging from $9-36$. For the purposes of this study, the researcher established a composite level of $9-27$ as indicative of a traditional teacher, Subgroup 1, and a composite level of $28-36$ as indicative of an inquiry-based teacher, Subgroup 2. The researcher determined the subgroups considering the 31 cases reporting data in the study, and determining relatively equivalent subgroups of traditional teachers and inquiry-based teachers. According to this quantified composite delineation, 17 teachers $(54.8 \%)$ qualified as traditional teachers, and 14 teachers $(45.2 \%)$ qualified as inquiry-based teachers. The researcher made this determination considering that a low case inquiry-based teacher would utilize these practices on at least a, "Some" to "Frequent" rating, $77 \%$ of the reported time.

This study was limited in its interpretation of these two subgroups, because it considered only the responses to instrument items in order to label the individual according to a single teaching practice. The researcher understands that the participants categorized into either subgroup are not necessarily purely traditional or inquiry-based teachers, utilizing a single pedagogical practice across the spectrum of their practice. A determination was necessary to develop these dimensions and thus begin analysis in relationship to the integration of technology.

\section{Statistical Measures}

In order to interpret the results of this study, a quantitative analysis of the data was conducted to allow for a descriptive and inferential examination of the study to take place, in the intent to best answer the research questions. Categorical data was collected according to item sets, previously described in the instrumentation section. Participants 
responded according to scale ratings of their perception of practice according to frequency of the descriptor. The categorical data was then assigned values, to quantify the ordinal measure of the practice. The values assigned were then interpreted as an aggregated score according to a composite of the set of items pertaining to the research question. The composite score was then considered as a single entity representing the concept of that participant's perception of the practice. Each participant's composite score value was then considered as a part of their subgrouping's overall indicator of the perception. Finally, the individual subgroups' measure of the central tendency was conducted per item set composite, and then inferential analysis of significance between means was calculated to determine any identifiably significant differences between the subgroups data existed.

Within this study, it is justified that categorical data was interpreted through the assignment of values, to quantify ordinal responses to levels of perception. Within the field of social science, categorical data is often interpreted as interval data to allow for the quantifiable interpretation of a difference (Schutt, 2009; Shortell, 2010). The purpose of this study was to identify the difference between responses to concerns and perceptions of integration practices according to the subgroup variables of pedagogical practices. To do so, the participants results were interpreted from a composite of responses in related items of a particular variable, as identified in the research question.

The study used an independent samples t-test to consider the difference between the two identified subgroups as the independent variables of consideration, while holding the dependent variable of concern for technology integration, the innovation, as the constant. The researcher calculated a level of significance between the means of the 
independent variable in the analysis to consider relationships according to the presented hypotheses.

Next, the researcher considered each subgroup's significance level for relationships to the hypotheses, bearing in mind the degrees of freedom allowed $(\mathrm{df}=30)$. Consideration of a statistical significance of differences between means was determined between subgroups. The subgroups do not directly indicate the sample groups' representation of the overall population's beliefs towards the integrated technology within the study. The researcher considered this possibility within the study, and has thus justified the items in Part 2 of the study as critical to a more conclusive determination of the level of individual participant's use of inquiry-based learning practices, as well as their level of self-perceived technology integration.

To address the first research question the researcher considered results from Part 1: Stages of Concern Questionnaire. For the purposes of this study, the researcher summated the SoC profile data as a total out of 280 possible scale points, summating the 35 items each with an eight point Likert-scale range of response, to provide a total composite measure of concern ranging from hierarchical values of 35-280 points. The researcher used summative practices in this study to identify an overall level of concern about the innovation, technology integration. The researcher analyzed the dependent variables according to the research question in comparison to the pedagogical practice. The researcher developed one generalizable concern level, consisting of all levels of concern identified by George, Hall, and Stiegelbauer (2006).

In order to produce findings for research question one, the researcher considered this interval data and calculated a central tendency, mean according to the number of 
participants within each subgroup. The average level of concern scores from each subgroup were then compared using a standard independent samples t-test to consider any identifiable relationships present between the level of concern for the innovation of technology integration and the pedagogical practice.

For the purposes of research question two, the participants determined their frequency of use of technology. The researcher named the dependent variable in this test as the frequency of use. The independent variable remained the same as in research question one, the two pedagogical practices in consideration. The researcher summated a composite of frequency of use scores of each individual's data response to items 6 and 7 . The researcher based the summation on the eleven uses posed out of a hierarchal value range of 5-44. The researcher noted that the higher the value, the more indicative of the highest level of technology-integration frequency. The researcher then assigned raw composite scores to the participants' subgroups, and averaged these according to the central tendency, mean according to the number of participants within each subgroup. In order to determine relationships for research question two, the researcher conducted a standard independent samples t-test considering the subgroups central tendency descriptors.

For the purposes of research question three, the researcher identified the depth of the participants' integration practices. Next, the researcher summated the individual participant's Likert-scale reporting in the application cases, item $13-16$, with a possible value range of $4-16$, and exempted missing responses to assign a composite score for each participant. The researcher assigned these composite scores to the participants' corresponding subgroups, and averaged these according to the central tendency, mean 
according to the number of participants within each subgroup. The researcher then analyzed the mean scores of each subgroup through an independent samples t-test, to determine the level of significance between the means of the subgroups in regards to their depth of integration application.

The process of statistical analysis described within this study determined by the focus of the research question to identify differences that occur according to level of significance. A similar format of analysis was involved in all three research question considerations, with different item sets and variables. The subgroup comparison for significance supports the researcher in determining the level of significance between pedagogical practices and technology integration internal level of concern and perception of practice.

Consideration of the Hypotheses Posed

The table below, Table 2: Data source of analysis, summarizes the research questions posed, how each question was addressed through quantitative data collection, as well as, the analysis procedures conducted to draw conclusions. 
Table 2

Data source of analysis

\begin{tabular}{|c|c|c|}
\hline Research Question & Data Source & Analysis \\
\hline $\begin{array}{l}\text { Do differences occur between } \\
\text { the beliefs/concerns of inquiry- } \\
\text { based teachers and traditional } \\
\text { teachers about integrating } \\
\text { technology to enhance student } \\
\text { learning? }\end{array}$ & $\begin{array}{l}\text { Part 1: Stages of } \\
\text { Concern Questionnaire }\end{array}$ & $\begin{array}{l}\text { t-test for independent } \\
\text { means } \\
\text { consideration of level of } \\
\text { concern toward } \\
\text { integrating technology }\end{array}$ \\
\hline $\begin{array}{l}\text { Do differences occur between } \\
\text { the perceived use of technology } \\
\text { of inquiry-based teachers and } \\
\text { traditional teachers? }\end{array}$ & $\begin{array}{l}\text { Part 2: Evaluating the } \\
\text { Use of Technology } \\
\text { within Pedagogy }\end{array}$ & $\begin{array}{l}\text { Independent samples t- } \\
\text { test } \\
\text { Consideration of } \\
\text { frequency of use }\end{array}$ \\
\hline $\begin{array}{l}\text { Do differences occur between } \\
\text { the perceived technology } \\
\text { integration practices of inquiry- } \\
\text { based teachers and traditional } \\
\text { teachers? }\end{array}$ & $\begin{array}{l}\text { Part 2: Evaluating the } \\
\text { Use of Technology } \\
\text { within Pedagogy }\end{array}$ & $\begin{array}{l}\text { Independent samples t- } \\
\text { test } \\
\text { Consideration of } \\
\text { application of practice }\end{array}$ \\
\hline
\end{tabular}

The research methodology utilized within this study was quantitative by nature, intending to measure correlation of technology integration practices with the pedagogical preferences of practitioners. The instrument design included two parts that measured the internal stages of concern the practitioner had towards integration and the outward perception of practices to integrate technology according to self-reporting data from the participant. The statistical analysis involved collecting categorical data, organized through ordinal scales of measure interpreted through interval values measured by composite scoring. Inferential measures of analysis were conducted to determine a measure of significance of difference between pedagogical practice subgroups relating to the research questions posed. 


\section{CHAPTER IV}

\section{RESULTS}

The results of this study inform the research questions concerning the process of integrating technology into the learning process from the perspective of practitioners. The results are organized by the research questions posed, first considering the concerns practitioners have towards implementing the innovation, then the perceived use of integration practices in authentic and enriching ways, and finally in the application of integration practices in proposed settings according to the SAMR model. The study aimed to identify differences that may exist between the concerns and perceptions of these two varying practitioner groups to draw conclusions based on the findings about best practices in integrating technology looking for aligning with instructional methods.

\section{Subgroup Identification}

The researcher organized the participants into subgroups according to criteria establishing the preferential teaching practice as the independent variable. The independent groups described previously in chapter three were determined as a result of the study, rather than as an incumbent variable. A standard of measure was identified amongst the composite score results of the teaching method practice questions posed.

The composition of each subgroup was diverse to their setting, grade-level taught and years' experience with the innovation of integrating technology into learning (Table 3). Within the traditional group 59\% of participants reported having formal training on 
the innovation of integrating technology, according to the SoC Questionnaire, while 64\% of inquiry-based teachers reported having had formal training with this particular innovation. The overall demographics of the two subgroups is taken into consideration as alternative variables of influence, as well as to better understand the practitioners categorized according to the particular pedagogical practice according to their perceptions of preferred instructional method reported.

Table 3

Demographics of study sample

\begin{tabular}{ccc}
\hline \multicolumn{2}{c}{ Percentage of Teachers } \\
\hline Traditional & $\begin{array}{c}\text { Inquiry-based } \\
(\mathrm{n}=17)\end{array}$ &
\end{tabular}

Type of School

International $\quad 64.7$

Illinois public

35.3

Years of experience

$1-5$

6-10

11-15

16-20

21-25

26-30

31 or more

Level of current teaching position

Elementary school

Middle school

High school

Multiple levels
35.2

11.8

17.6

0.0

41.1

0.0

0.0

29.4

23.5

35.3

11.7

28.6

28.6

0.0

28.6

7.1

7.1

0.0

Formal training integrating technology

Yes

58.8

64.3 
Participants also reported their years of implementing the innovation of technology integration on the SoC Questionnaire, using a six-point scale ranging from "Never" to "5 or more years" of use. The subgroup of traditional teachers reported a median score of 3 years of use with technology integration and inquiry-based teachers reported a median score of 4.5 years of use of the innovation of technology integration. The researcher found that inquiry-based teachers reported 1.5 years more of using the innovation of technology integration. The years of innovation reported were taken into consideration in the discussion.

\section{Findings and Results}

Research Question 1: Comparison of Level of Concern towards Technology Integration

Research question 1 examines whether any differences occur between the beliefs/concerns of inquiry-based teachers and traditional teachers about integrating technology to enhance student learning. The first directional hypothesis, determined by the researcher predicted that a significant difference would occur between the concern levels, and the inquiry-based practitioners would demonstrate a higher level of concern over technology integration, beyond the extent that the traditional practitioners would experience.

A composite score of all stages of concern was calculated, for each participant quantifying the categorical Likert-scale representation of their concern level. A total of 280-point scale was used. The composite scores of each participant were compiled within the two subgroups and the researcher first compared the means of the two 
subgroups overall levels of concern, as measured by their responses to the $\mathrm{SoC}$

Questionnaire. As indicated in Table 4, the results of analysis show the higher mean level of concern, of the inquiry-based teachers $\left(\mathrm{X}_{2}=139.43\right)$, than traditional teachers group mean level of concern $\left(X_{1}=129.65\right)$. The inquiry-based teachers group reported a higher level of concern, on average, over the traditional teachers $\left(X_{2}-X_{1}=9.78\right)$.

Table 4

Descriptive analysis comparing stages of concern

\begin{tabular}{lcccc}
\hline Groups & $\mathrm{n}$ & $\mathrm{X}$ & $\mathrm{SD}$ & Skewness \\
\hline Traditional teachers & 17 & 129.65 & 29.41 & -.32 \\
Inquiry-based teachers & 14 & 139.43 & 34.18 & -.23 \\
\hline
\end{tabular}

The researcher conducted an independent samples t-test to determine if a significant difference existed between the mean technology integration concern levels of traditional teachers and inquiry-based teachers. Sample variances were equal for the independent samples t-tests indicating that the variations of the two populations are approximately equal. With equal variances assumed $(\mathrm{p}>0.05)$, there was no statistically significant difference between the mean technology integration concerns of traditional teachers group $(\mathrm{n}=17, \mathrm{X}=129.65)$ and inquiry-based teachers group $(\mathrm{n}=14, \mathrm{X}=$ 139.43), $(\mathrm{t}(29)=-.86, \mathrm{p}=.40)$. The researcher failed to reject the null hypothesis. No significant difference existed between respondents' reported pedagogical practices in relation to concern over technology integration. Inquiry-based teachers group and traditional teachers group reported similar pedagogical practices in relation to their level of concern over the innovation of technology integration. 


\section{Research Question 2: Comparison of Frequency of Use of Technology}

Research question 2 examines whether any differences occur between the perceived use of technology of inquiry-based teachers and traditional teachers. The second directional hypothesis, determined by the researcher predicted that a significant difference would occur and the inquiry-based practitioners would express a more frequent level of technology use, beyond the extent that the traditional practitioners would.

The researcher utilized Part 2 of the instrument, Evaluating the Use of Technology within Pedagogy, to determine the overall use of technology. In order to do this, the researcher quantified the responses to items 6 and 7 with an ordinal value according to the frequency of use, ranging from $5-44$ points. Participants having a higher point value on the 11 situations presented aligned with a more frequent use of technology. In this study, the participants' level of technology use ranged from $8-36$ points.

The results of analysis show the higher mean level of using technology of the inquiry-based teachers $\left(X_{2}=26.14\right)$, than the traditional teachers' mean level of use $\left(X_{1}=\right.$ 20.94) (Table 5). The inquiry-based teacher group reported a higher level of use, on average, over the traditional teacher group $\left(X_{2}-X_{1}=5.2\right)$. The researcher found that the central tendencies varied by a notable range, as did the standard deviation of the two subgroups $\left(\mathrm{SD}_{2}-\mathrm{SD}_{1}=3.7\right)$. These differences are important to consider because the traditional teacher group's standard deviation is nearly twice the deviation of the data in the inquiry-based teacher group. Within the subgroups, the individual traditional teachers 
reported use of technology varied, moreover the individual teachers within the inquirybased subgroup whom reported technology use more uniformly.

Table 5

Descriptive analysis comparing frequency of use

\begin{tabular}{lcccc}
\hline Groups & $\mathrm{n}$ & $\mathrm{X}$ & $\mathrm{SD}$ & Skewness \\
\hline Traditional teachers & 17 & 20.94 & 8.44 & .30 \\
Inquiry-based teachers & 14 & 26.14 & 4.74 & .02 \\
\hline
\end{tabular}

The researcher conducted an independent samples t-test to determine if a significant difference existed between the mean frequency of using technology of traditional teachers and inquiry-based teachers. The researcher used an alpha level of .05 for all statistical measures to determine variance. With consideration that the confidence of is not assumed, there was a statistically significant difference between the mean technology use of traditional teachers $(n=17, X=20.94)$ and inquiry-based teachers $(n=$ $14, \mathrm{X}=26.14),(\mathrm{t}(29)=-2.16, \mathrm{p}=.04)$. The researcher accepted the directional hypothesis. The outcome of this t-test indicated that there was significant difference between pedagogical practices in relation to the use of technology.

Research Question 3: Comparison of Technology Integration Application

Research question 3 examines whether any differences occur between the perceived technology integration practices of inquiry-based teachers and traditional teachers. The third directional hypothesis was that the inquiry-based practitioners would demonstrate a higher level of technology integration practices, beyond the extent that the traditional practitioners would apply. 
The researcher utilized Part 2 of the instrument, Evaluating the Use of Technology within Pedagogy, to determine an overall application of true integration practices, as described in chapter three. The researcher first determined the dependent variable, to answer research question three, as the applied level of technology integration. In terms of the instrument, the means are representative of the participants' depth applying technology integration, considering an ordinal ranking, with a higher mean indicating more in-depth integration practices. The values identified were that of a ranking ordinal measure for four items, ranging from possible values of 4-16 points. This is important to consider when analyzing the mean and spread of data.

As indicated in Table 6, the results of analysis show the higher mean level of integration practices of traditional teachers $\left(X_{1}=9.00\right)$, than the traditional teachers group mean level of integration $\left(X_{2}=7.75\right)$. The traditional teachers reported a higher level of use, on average, over, inquiry-based teachers $\left(\mathrm{X}_{1}-\mathrm{X}_{2}=1.25\right)$. It is important to note in this test, the sample size for both subsamples decreased, because participants did not respond to questions that pertained to a topic outside of their current area of practice.

Table 6

Descriptive analysis comparing technology integration application

\begin{tabular}{lcccc}
\hline Groups & $\mathrm{n}$ & $\mathrm{X}$ & $\mathrm{SD}$ & Skewness \\
\hline Traditional teachers & 10 & 9.00 & 3.89 & 1.08 \\
Inquiry-based teachers & 12 & 7.75 & 2.09 & 0.90 \\
\hline
\end{tabular}

The researcher conducted an independent samples t-test to determine if a difference existed between the application technology integration of traditional teachers and inquiry-based teachers. Sample variances were equal for the independent samples t- 
tests indicating that the variations of the two populations are approximately equal. There was no statistically significant difference between the mean application of technology integration of traditional teachers $(n=10, X=9.0)$ and inquiry-based teachers $(n=12, X$ $=7.75),(\mathrm{t}(20)=.96, \mathrm{p}=.35)$. The researcher accepted the null hypothesis. The outcome of this t-test indicated that there was no significant difference between pedagogical practices in relation to integrating technology. Inquiry-based teachers' and traditional teachers' pedagogical practices were similar in relation to their applying integration practices.

\section{Summary}

Overall, the researcher determined no statistically significant difference between subgroups of traditional and inquiry-based teachers, regarding concern level towards technology integration. The researcher found a statistically significant difference between traditional and inquiry-based teachers according to their currently reported use of technology integration. Finally, the researcher found no statistically significant difference between the means of the subgroups on the dependent variable, measuring application of technology integration practices. These results inform the literature presented and support the hypotheses accepted to determine understandings accordingly to the research questions posed. 


\section{CHAPTER V \\ DISCUSSION AND CONCLUSION}

The results of this study inform the three research questions posed.

Research Question 1: Do differences occur between the beliefs/concerns of inquiry-based teachers and traditional teachers about integrating technology to enhance student learning?

Research Question 2: Do differences occur between the perceived use of technology of inquiry-based teachers and traditional teachers?

Research Question 3: Do differences occur between the perceived technology integration practices of inquiry-based teachers and traditional teachers?

The study found that the level of concern over technology integration does not significantly differ among teachers based on their preferred method of instruction. It found that there was a significant difference over the perceived use of technology for inquiry-based teachers compared to traditional teachers. The level of perceived ability to integrate technology is not significant with either inquiry-based teachers or traditional teachers.

This study contributes to the body of knowledge necessary to identify bestpractices of pedagogy while truly integrating technology within learning. Contributions are made to understandings of practitioners' attitudes, including the beliefs and concerns they have towards the integration of technology into their instructional practice. Also, 
this study offers further understanding how concerns are interpreted through the practitioners reported perception of technology use and application of integration practices.

In this discussion, the researcher interprets findings from the study within the context of the literature. First, an exploration of the relationship between pedagogical practice and teacher concern over technology integration occurs. Next, the researcher compares the significant findings over technology use with the non-significant findings of integration practices. Then, a review of the problem over methodology to approach integration is presented. Finally, the researcher shares the limitations of the present study.

Theme 1: Pedagogical Practices and Concern over Integrating Technology The researcher found no significant difference between the beliefs/concerns of inquiry-based teachers and traditional teachers in regards to integrating technology. One possible explanation of this result is that both groups are still at an awareness/unconcerned level of technology use. Both groups reported approximately $60 \%$ formal training with the innovation, leading the researcher to understand that nearly a third of each subgroup had no formal training on integration of technology practices. A lack of formal training may describe the lack of awareness concern for both groups. Another explanation could be that the overall sample population's years of teaching experience, with nearly half reporting less than 10 years of experience (48\%). Johnson's (2007) longitudinal study of perceived change of technology use by kindergarten through 12 teachers identified teaching experience as the only variable found as a significant factor to technology integration. It is unclear, when considering the results of the current 
study, if the sample population's years of experience played a significant role in their ability to effectively integrate technology. To further analyze this finding, an even longer period of use of integration practice, or a comparable amount of experience between each group, may be necessary to determine significance between either pedagogical practice group. This brings up the question if there is a difference between years of experience and the concern over technology integration. Further study considering practicing teachers using inquiry, and comparing a concern over the integration of technology would be useful to determine if there is a true correlation between the two. Likewise, further study on how long it takes to effectively integrate technology would be useful to clarify the results of this present study, in order to differentiate between pedagogical practices.

The present study's findings confirm findings of prior studies specifically Ertmer et al. (2007). Ertmer et al. (2007), reported that, "inner drive and personal beliefs $(\mathrm{M}=$ 4.84) were rated the most influential" technology integration barriers (pp 56-57). The present study's findings reflect the internal locus of barriers described as prominent by Ertmer's findings. Since the differences between findings over level of concern and application of integration practices were not significant, the results of research questions one and three may be tied, informing the researcher to a potential explanation of why no significance was found between the practitioner groups in their internal concerns and perception to apply technology integration practices.

The present study's findings differ from findings of Clark's (2002) dissertation that a positive, significant difference occurred over integrating technology with preservice teachers using inquiry-based practices. The sample population selection is the 
clear difference between the present study and Clark's study. The present study was inclusive to in-service teachers only, while Clark's study examined pre-service teachers. The difference in sample population could be an explanation to why the studies found different results. All of the pre-service teachers had been through formal training with the innovation of integration technology into instructional practice. Clark lists a limitation to her study, that "expert teachers" must be able to model the skills and strategies necessary to effectively integrate technology. At the time of Clark's study, fewer practicing teachers routinely used computer-based technology for instructional purposes (Clark, 2002).

An explanation for not rejecting the null hypothesis in research question 1 is not entirely clear; the most likely explanation is that the sample of the population was not large enough, or accurate of "pure-bred" pedagogy to study the single pedagogical method in isolation, comparative to technology integration. Just as all learners are unique, all practitioners are as well, and their personal teaching concerns, style/use, and application will vary. It may be beneficial to future research on the topic to consider individual case studies of successful integration, and then analyze the pedagogical methodology employed. The reversal of the study, knowingly studying integration and then analyzing the pedagogical practice, may foster an understanding of components of practice that are necessary to integration.

The implications of these findings indicate that the teachers' method of instruction does not necessarily imply that they will have a higher level of concern over integrating technology over other teachers using an alternative method of instruction. The concerns of a teacher using inquiry-based practices are not significantly different 
from the concerns of a teacher using traditional practices. Also, inquiry-based and traditional teachers are not significantly different in their application of integration practices, as determined by the results of research question 3 .

Theme 2: Use of Technology Does Not Indicate Integration

One of the major concerns addressed over technology use in the literature was if teachers' practice of integrating technology was effecting learning in authentic and enriching ways (Bull, 2009; Clark, 1984; Kim, 2012; Morrison \& Lowther, 2010; Mishra \& Koehler, 2006; Puentedura, 2013). This is where the differentiation between technology use and technology integration is paramount. The integration process, in its true nature, intends to transform the learning experience in a way that is authentic and enriching. This study aimed to determine if a particular pedagogical practice, specifically inquiry-based learning, would support a difference in perception over technology use and application of integration practices.

The researcher explored the present data to reveal that a statistically significant relationship exists $\left(\mathrm{t}_{(29)}=-2.16, \mathrm{p}=.04\right)$, between inquiry-based teachers and traditional teachers, in regards to the perceived use of technology. This finding measured reported frequency of use only and cannot generalize to the method of using the technology. The inquiry-based teachers reported using technology in authentic and enriching ways more frequently than traditional teachers, and that this relationship of use was significant. Use of technology does not necessarily mean integration. This was the case when comparing inquiry-based teachers and traditional teachers in regards to technology integration and finding no significance variance. Both, traditional teachers and the inquiry teachers integrated technology to similar degrees. 
The present study further clarifies the findings of the study by Tondeur et al. (2013). Tondeur's methodology included observations and simulated recall interviews, with findings that technology use does not indicate integration. The findings of this present study, using a survey methodology, found similar results that no matter what the pedagogical practice, teacher's perceived use of technology did not translate directly to likened integration practices. To complement Tondeur's methodology, where beliefs and concerns were inferred from the teachers' actions and speech in observation, the present study directly asked the practitioners about their beliefs and concerns, and found similar results. Findings of two studies (Sanchez, 2011; Sharples \& Anastopoulou, 2012) regarding mere use of technology, or even significant use of technology, determined that these participants were not all necessarily integrating technology. These findings are reverberated in the present study. It is a completely different thing to integrate technology to transform learning (Puentedura, 2013).

One consideration of the results regarding use versus integration may be that the two independent variable groups defined by the researcher in this study were in-fact not diverse enough to pinpoint the difference between use and use to the level of true integration. Teachers from the same school settings were represented in both groups. The two groups of teachers also had an over-representation of elementary teachers comparative to the other backgrounds of kindergarten through 12 levels of teachers. Most importantly, to provide more diversity or to distinguish the groups further a deeper understanding or survey of the participants' pedagogical practices could have been analyzed to strengthen subgrouping procedures. Teacher practitioners cannot be defined by any one specific pedagogical practice in isolated variable. There may not be a single 
identifiable best-practice of instruction cohesive to integrating technology effectively. Integration is with use implied, to another level, which the capacity of this study may not have been able to measure.

Implications of this study's findings indicate that practitioners, utilizing all different sorts of pedagogical practices, all require support and training in the practice of technology integration. While inquiry-learning may afford more technology use, the ultimate goal of technology on the education landscape is integration. This study can inform teacher preparation objectives on the differences between use and integration within the instructional practices of choice.

Further considerations should be made on why true integration is not occurring, regardless of pedagogical practice. A new question arises: Are there additional pedagogical practices that, like inquiry, afford more technology use and are even more conducive to integration practices? It is likely that some pedagogical methods are better aligned with integration practices; yet, this study did not find significance between the two methods analyzed. Further study would be useful in considering alternative pedagogical practices.

\section{Theme 3: Orchestrating Learning}

The present study found no significance between the inquiry-based teachers and traditional teachers' perceptions concerning the practice of integration. The traditional teachers indicated a higher average level of integrative application over the inquiry-based teachers, which is unique to the other test results of this study. So, inquiry alone, and technology alone, may not be independently substantial. Practitioners within this study 
reporting higher integration practices did not necessarily disclose a higher level of concern or use than teachers who reported lower integration practices.

A major theme found throughout the literature is the concept of orchestrating learning (Littleton, et al., 2012; Scanlon, et al., 2012; Viilo, et al., 2012). Orchestration encompasses inquiry-based learning, in tandem with technology integration, with the ultimate intention of improving learning. The pedagogical design of orchestration focuses on the role of the practitioner in analogy with the conductor of an orchestra. The orchestrating practitioner is different than that of a traditional teacher implementing direct instruction and explicit guidance. Orchestration encompasses the ability of the practitioner to focus on process of learning, as presented in inquiry-based learning, defined within this study.

Alfieri et al. (2011) identified only "enhanced inquiry" as a best-practice using guiding and scaffolding, which technology allows. Alfieri's study found that outcomes were actually favorable for explicit instruction when compared to unassisted inquiry, but overall, it enhanced inquiry over other methods. The present study found similar results, indicating the possibility that practitioners in the inquiry-based group are either (a) not implementing enhanced inquiry, which reflects on the integration practices, or (b) the inquiry practices used with the technology do not make use of integration practices.

Crippen and Archambault (2012) found technology to provide the infrastructure for inquiry, serving as the platform on which scaffolding inquiry learning takes place. The understanding of technology as the platform almost looks at the present study from a reverse view. The present study did not asses this reversal perception and further study of this phenomenon may be necessary to clarify the present results. 
Littleton, Scanlon, and Sharple's (2012) comprehensive literature review identified a significant competence and level of beliefs essential to accurate inquiry-based teaching methods using technology. The present study may confirm this finding in that the inquiry-based teachers did not express significantly different attitudes of overall use of technology from traditional teachers across the board in areas of concern and use of technology; thus, it is likely that they would not be significantly different in the area of integration, as well.

The expectation remains for teachers in kindergarten through 12 schools to integrate technology, yet this study failed to produce firm recommendations regarding best practices of methodology. The implications of this study indicate a potential for practitioners to use technology more within inquiry-based learning environments. Buckner and Kim (2013) indicated that "many ICT [information and communications technology] projects, particularly in the developing world, are limited by the lack of integration between pedagogy and technology" (p. 3). This disconnect or limitation that Buckner and Kim mention can be a deeper problem than just searching for a best-fit model for pedagogy and technology. This mirrors Fullan's (2011) findings that technology cannot be an anchor driving effective culture change in the education field; pedagogy can drive the change in the culture of a system. While the pedagogical practice of inquiry is an alternative method, it may not necessarily ensure the practice of technology integration. Teacher preparation reform efforts, variation of approaches, and positive concerns on the teacher's behalf to utilize new models of inquiry-based learning, all have the potential to influence the practitioner's ability to integrate technology effectively in the classroom. 
The themes explored within this study are not exhaustive by any means. The intent was to cross-examine the results of the three research questions considered when exploring the concerns of practitioners towards integrating technology into instruction. The results of the study add to the literature on interplay between pedagogical practice preferences and perceived application of technology integration practices in transformative ways.

\section{Limitations}

A number of limitations require attention when interpreting the results of the current study. The limitations of the study influenced the areas of data collection, instrumentation, and the data interpretation procedure. The limitations are disclosed and further discussion is detailed on the effects these limitations potentially had on the study.

First, there are limitations to conducting survey research. The wording within survey research questions may affect different participants in different ways, due to their individual interpretation of the item or direction set. There is also room in survey research for unconscious bias to be setup within the item set (Fraenkel \& Wallen, 2009). Within this study, the findings completely depend on the self-reporting of teachers, which may not represent the actual behaviors or present practices.

The second limitation relates to the medium of survey distribution. Due to the nature of the tool utilized, the researcher would recommend using an electronic form if a replication of this study is completed. The electronic form has the possibility of minimizing the margin of error, increasing the number of participants, and shortening the response time. The use of hardcopy, paper and pencil, surveys provided a greater margin of error on the place of the participant, intentionally, as well as, unintentionally. For 
future research, recommendations framing an online survey will remedy a majority of the user errors encountered with this survey tool. Participants did not consistently follow the directions for completing the tool. With the use of an electronic survey format, the individual can be prevented from selecting more than one response. This caused a variety of invalid and thus unusable data. Within this study, $56 \%$ of participants made multiple sections when a single response was requested, rendering their response for that item invalid. An online survey tool, or electronic survey would only accept survey responses and not additional feedback. Within this study, $34 \%$ of participants added unsolicited qualitative feedback. While this can be viewed positively for the researcher's perspective as a method of receiving more feedback, it does not support the analysis of quantitative data. Additionally, the response time frame could be shortened when less effort is required. The hardcopy format required these participants to print, complete, scan and send back the survey, which allows for multiple windows of time when the participant may choose to terminate their participation. By providing an electronic form of submission there will be a reduction of required elements on the part of the participant.

The third limitation to consider is the design of Part 2 of the instrument. The researcher acknowledges the limitations of using a new tool with no pilot study to test for reliability of the instrument items. Concerns arose in the analysis phase of research and it became necessary to remove items from consideration of use and application. Survey items 8 through 12 were not considered in the analysis directly related to the research questions. Another possible explanation for no significant variance between the two subgroups could be a flaw within the instrument design. It is possible that the flaw within the instrument, specifically the item design, asked only surface level questions 
about inquiry and did not get to the implicit nature of inquiry, which could explain why subgroup variance was not diverse.

The fourth limitation the researcher considered is the overall population surveyed and the method of subgrouping. Due to the small sample size, caution is warranted in interpreting results, and applying these findings to other populations. The researcher determined a subgrouping method was necessary to avoid assumptions based on practice as indicative of setting. The dimensions established to determine subgroups considered the possibility of outlying responses from individuals on their practice. It is necessary to consider that participants grouped as traditional teachers do not necessarily refrain from any inquiry-based practices and that the participants grouped as inquiry-based teachers do not refrain from traditional practices. As mentioned in theme 2, it is a possibility, within the limitations of this study, that the grouping method utilized was an imperfect process that produced groups that are, in-fact, too similar. Unexpectedly, all of the participants within this study reported the use of inquiry-based practices. Further specification to define "inquiry" is necessary. If all of the participants were demonstrating aspects of inquiry, then this may explain why little significant difference occurred throughout the study.

The fifth limitation to consider was the amendment of the SoC Questionnaire, from the original intended purpose. The researcher acknowledges that the instrument design was to determine a specific level and type of concern, as well as allow for interpretation about the individual participants response to the innovation. The researcher should give consideration to each of the seven stages of concern within the subgroup profile, when utilizing this tool. For the purposes of this study, the instrument was used 
to determine a level of concern for the innovation overall. In order to interpret an overall level of concern, not dependent on type of concern, a summation of all items according to their individual scales was determined for each participant. The researcher identified this summation of overall response as the numerical representation of concern, which then was associated with the generalized concern on implementation of integrating technology.

The researcher acknowledges the limitations, errors and flaws within this study and interprets the findings in view of these conditions. It is important to provide transparency to these various limitations in order to allow for further interpretation of this present study. Also, future researchers can make considerations on how to modify this study upon replication to clarify or improve the quality of the results.

\section{Conclusions}

This research study found that (1) the level of concern over technology integration is neither significant for the inquiry-based teachers nor the traditional teachers; (2) a significant difference occurred over the perceived use of technology for inquiry-based teachers, in relation to traditional teachers; and (3) the level of perceived ability to integrate technology is neither significant with inquiry-based teachers nor traditional teachers.

In general, results of the present study confirm those of past research (Anastopoulou \& Kerawalla, 2012; Chinn \& Malhotra, 2002; Sanchez, 2011; Tondeur et al., 2013). Although a single pedagogical method does not appear to define the culture of technology integration, one may ponder whether there is a best-practices approach to integrating technology. This research contributes to the concern to determine the most 
effective ways to integrate technology, by providing more insight into practitioners' decisions to integrate technology in the learning process.

This study on inquiry-based learning with integrating technology into the learning process shows potential for the interplay between the instructional method and practice. Key components of inquiry-based learning, such as asking essential questions, critical thinking, the collection of information, effective analysis and synthesis of new information to produce results, align with the capabilities that technology has to offer, and the technology standards that have been developed, thus seemingly can be integrated into this learning style (ISTE, 2007). For further study, the researcher recommends the use of an observation methodology, to collect data on the experience of the two practices hand in hand.

This study's findings were important because practitioners make choices on a daily bases to do what is best for their students. This study aimed to support this decision-making in an effort to explore an alternative teaching approach that is the most practical for goals of technology integration. The hypothesis of this study was not to claim a superior method of instruction but to gain insight into the practitioner perception of how their method aligns with integration. We now know that the perceptions of practitioners continue to be influential regarding decision making in technology integration, alongside practitioner technology use for the foundation of integration.

If technology integration is compatible with a variety of methodologies, then a greater population of practitioners is likely to experience success in integrating, which may have been the case in this study. This study only looked for difference between the levels of integration and did not assess an overall level to a standard. To fill this gap, 
further research could determine a level of integration necessary for transformative learning, similar to what the SAMR model has alluded to, and then use this standard to compare the variable pedagogical practices accordingly.

The implications of this research study directly apply to practitioners in the field. This researcher recommends practitioners attempt a variety of instructional methodology approaches, including inquiry, to determine a personal, best-fit model for each unique group of learners. The end goal remains the same; educate students in a way that best meets their needs, as digital citizens on an education landscape, which is ever-changing. The purpose of integrating technology into the classroom is to empower learners to be successful, independent life-long learners. This may very well mean that teachers take on new roles within the learning process not necessarily designed in a one-size-fits-all fashion. 


\section{REFERENCES}

Alfieri, L., Brooks, P. J., Aldrich, N. J., \& Tenenbaum, H. R. (2011). Does discoverybased instruction enhance learning? Journal of Educational Psychology, 103(1), 1-18. doi: 10.1037/a0021017

American Association of Colleges for Teacher Education (AACTE). (2013). The changing teacher preparation profession. Retrieved from https://secure.aacte.org/apps/rl/res_get.php?fid=145

American Institutes for Research (AIR). (2013). Predictors of postsecondary success. Retrieved from http://www.air.org/resource/predictors-postsecondary-success

Anderson, R. E., \& Dexter, S. (2003). Newsome Park Elementary: Making learning meaningful through project-based learning using wireless laptops in a K-5 math, science and technology magnet school. U.S.A. Exemplary Technology-Supported Schooling Case Studies Project. Retrieved from http://edtechcases.info/schools/newsome/newsome.htm

Archambault, L. M., \& Barnett, J. H. (2010). Revisiting technological pedagogical content knowledge: Exploring the TPACK framework. Computers \& Education, 55(4), 1656-1662. doi:10.1016/j.compedu.2010.07.009

Bellanca, J. A., \& Brandt, R. S. (Eds.). (2010). 21st century skills: Rethinking how students learn. Bloomington, IN: Solution Tree Press.

Brantley-Dias, L., \& Ertmer, P. A. (2013). Goldilocks and TPACK. Journal of Research on Technology in Education, 46(2),103-128. doi:

$10.1080 / 15391523.2013 .10782615$

Buckner, E., \& Kim, P. (2013). Integrating technology and pedagogy for inquiry-based learning: The Stanford mobile inquiry-based learning environment (SMILE). Prospects Quarterly Review of Comparative Education. doi: 10.1007/s11125013-9269-7

Bull, G. (2009). Tutor, tool, tutee: A vision revisited. Contemporary Issues in Technology and Teacher Education, 9(2), 89-94. Retrieved from: www.citejournal.org/articles/v9i2editorial1.pdf 
Bybee, R. W. (2014). The BSCS 5E instructional model: personal reflections and contemporary implications. Science \& Children, 51(8), 10.

ChanLin, L. J. (2007). Perceived importance and manageability of teachers toward the factors of integrating computer technology into classrooms. Innovations in Education and Teaching International, 44(1), 45-55. doi:

$10.1080 / 14703290601090390$

Chinn, C. A., \& Malhotra, B. A. (2002). Epistemologically authentic inquiry in schools: A theoretical framework for evaluating inquiry tasks. Science Education, 86(2), 175-218. doi: 10.1002/sce.10001

Clark, F. T. (2002). Impact of the cognitive apprenticeship model on preparing preservice teachers to effectively plan for the use of technology in instruction (Doctoral dissertation). Retrieved from Pro-Quest Dissertations and Theses database. (UMI No. 3069489).

Clark, R. E. (1983). Reconsidering research on learning from media. Review of Educational Research, 53(4), 445-459.

Clark, R. E. (1994). Media will never influence learning. Educational Technology Research and Development, 42(2), 21-29.

Crippen, K. J., \& Archambault, L. (2012). Scaffolded inquiry-based instruction with technology: A signature pedagogy for STEM education. Computers in the Schools, 29(1-2), 157-173. doi: 10.1080/07380569.2012.658733

Crompton, H. (2014). ISTE standards in the research. Learning \& Leading with Technology, 41(6), 38-39.

Danielson, C. (2009). Implementing the framework for teaching in enhancing professional practice. Virginia: Association for Supervision and Curriculum Development.

Davis, F. D., Bagozzi R. P. and P.R. Warshaw. (1989). User Acceptance of Computer Technology: A Comparison of Two Theoretical Models. Management Science, 35(8), 982-1003. doi: 10.1287/mnsc.35.8.982

de Jong, T. (2006). Computer simulations: Technological advances in inquiry learning. Science, 312, 532-533. doi: 10.1126/science. 1127750 
Delavan CUSD \#703 (2014). Delavan school mission statement. Delavan, IL: Parker, M. Retrieved from http://www.delavanschools.com

digital age. (2011). In Cambridge Business English Dictionary, Cambridge University Press. Retrieved from http://dictionary.cambridge.org/us/dictionary/businessenglish/digital-age

Edelson, D. C., Gordin, D., N., \& Pea, R. D. (1999). Addressing the challenge of inquirybased learning through technology and curriculum design. Qtd. in Scanlon, E., Anastopoulou, \& Kerawalla, L. (2012). New York: Routledge.

Ertmer, P. A., \& Ottenbreit-Leftwich, A. T. (2010). Teacher technology change. How knowledge, beliefs, and culture intersect. Journal of Research on Technology in Education, 42(3), 221-251.

Ertmer, P. A., Ottenbreit-Leftwich, A. T., \& York, C. S. (2007). Exemplary technologyusing teachers: Perceptions of factors influencing success. Journal of Computing in Teacher Education, 23(2), 55-61.

Eurydice. (2011). Key data on learning and innovation through ICT at school in Europe 2011. Brussels, BE: Education, Audiovisual and Culture Executive Agency. doi:10.2797/61068

Federal Communications Commission. (2010). FCC enables high-speed, affordable broadband for schools and libraries.

Federal Communications Commission. (2014). FCC to invest additional $\$ 2$ billion in high-speed internet in schools and libraries [Press Release]. Retrieved from https://apps.fcc.gov/edocs_public/attachmatch/DOC-325403A1.pdf

Fisch, K. (Producer). (2006). Did you know? [Video File]. Retrieved from http://thefischbowl.blogspot.com/2006/08/did-you-know.html

Fives, H., \& Gill, M. G. (2015). International handbook of research on teachers' beliefs. New York: Routledge.

Fraenkel, J. R., \& Wallen, N. E. (2009). How to design and evaluate research in education $\left(7^{\text {th }}\right.$ ed.). New York, NY : McGraw-Hill, c2009; 7th ed.

Fuchs, C., \& Akbar, F. S. (2013). Use of technology in an adult intensive English program: Benefits and Challenges. TESOL Quarterly, 47(1), 156-167. doi: $10.1002 /$ tesq. 80 
Fullan, M. (2011). Choosing the wrong drivers for whole system reform. Centre for Strategic Education Seminar Series (Paper No. 204). East Melbourne Victoria: Mercer House. Retrieved from www.cse.edu.au

Furtak, E. M. (2005). The problem with answers: An exploration of guided scientific inquiry teaching. Science Education, 90(3), 453-467.

George, A. A., Hall, G. E., \& Stiegelbauer S. M. (2006). Measuring implementation in schools: The stages of concern questionnaire. Austin, Texas: SEDL.

Goodyear, P., \& Retalis, S. (2010). Technology-enhanced learning: Design patterns and pattern languages. Boston, MA: Sense.

Hakkarainen, K. (1998). Epistemology of scientific inquiry and computer-supported collaborative learning. (Thesis). Retrieved from Pro-Quest Dissertations and Theses database. (Order No. NQ41435).

Hakkarainen, K., Bollström-Huttunen, M., \& Hoffman, R. (2008). Teacher-researcher dialogue and expansive transformation of pedagogical practices. Nordic Journal of Digital Literacy, 3, 157-178.

Hall, G. E. (2010). Technology's Achilles heel: Achieving high-quality implementation. Journal of Research on Technology in Education, 42(3), 231-253.

Hammonds, L., Matherson, L. H., Wilson, E. K., \& Wright, V. H. (2013). Gateway tools: Five tools to allow teachers to overcome barriers to technology integration. Delta Kappa Gamma Bulletin, 80(1), 36-40.

Hermans, R., Tondeur, J., van Braak, J., \& Valcke, M. (2008). The impact of primary school teachers' educational beliefs on the classroom use of computers. Computers and Education, 51(4), 1499-1509.

Hew, K. F., \& Brush, T. (2006). Integrating technology into K-12 teaching and learning: Current knowledge gaps and recommendations for future research. Association for Educational Communications and Technology. doi 10.1007/s11423-0069022-5.

Hickey, D. T., \& Filsecker, M. (2012). Participatory learning assessment for organizing inquiry in educational videogames and beyond. In Littleton, K., Scanlon, E., \& Sharples, M. (Eds.), Orchestrating inquiry learning (pp.146-174). New York: Routledge. 
Holden, H., \& Rada, R. (2011). Understanding the influence of perceived usability and technology self-efficacy on teachers' technology acceptance. Journal of Research on Technology in Education (International Society for Technology in Education), 43(4), 343-367. Retrieved from http://files.eric.ed.gov/fulltext/EJ930317.pdf

Holzweiss, K. A. (2014). Using tech tools for learning with standards. School Library Monthly, 30(4), 13-17.

Hsu, H., Wang, S., \& Runco, L. (2013). Middle school science teachers' confidence and pedagogical practice of new literacies. Journal of Science Education and Technology, 22(3), 314-324.

Hsu, Y.-C., Ho, H. N. J., Tsai, C.-C., Hwang, G.-J., Chu, H.-C., Wang, C.-Y., \& Chen, N.-S. (2012). Research trends in technology-based learning from 2000 to 2009: A content analysis of publications in selected journals. Educational Technology \& Society, 15(2), 354-370.

Illinois State Board of Education. (2013). Illinois Report Cart. Retrieved from http://www.isbe.s http://www.isbe.state.il.us/tate.il.us/

Illinois State Board of Education (2014). Illinois Common Core Standards. Retrieved from http://www.isbe.state.il.us/common_core/default.htm

Inan, F. A., \& Lowther, D. L. (2010). Factors affecting technology integration in K-12 classrooms: A path model. Educational Technology Research and Development, 58(2), 137-154. doi:10.1007/s11423-009-9132-y

International Baccalaureate Organization. (2014). International baccalaureate primary years program. Retrieved from http://ibo.org/programmes/pd/qualifications/

International School of Ulm/Neu-Ulm (2011). International school of Ulm/Neu-Ulm mission statement. ( $2^{\text {nd }}$ ed.). Neu-Ulm, Germany: International School of Ulm/Neu-Ulm.

International Society for Technology in Education (ISTE). (2000). National educational technology standards for teachers. Retrieved from

http://www.iste.org/docs/pdfs/nets_for_teachers_2000.pdf

International Society for Technology in Education (ISTE). (2007). National education technology standards for students. Retrieved from https://www.iste.org/

International Society for Technology in Education (ISTE). (2008). National education technology standards for teachers. Retrieved from https://www.iste.org/ 
International Society for Technology in Education (ISTE). (2012). Home of the NETS. Retrieved from https://www.iste.org/

International Society for Technology in Education (ISTE). (2013). ISTE Standards $\bullet S$. and ISTE Standards $\bullet$ T. Retrieved from http://www.iste.org/standards

International Society for Technology in Education (ISTE). (2014). Journal of research on technology in education. Retrieved from www.iste.org/JRTE

Johnson, P. (2007). Longitudinal study of change in classroom practices of technology use by K-12 teachers. Technology and Teacher Education Annual, 3, 1536-1541.

Joubert, M., \& Sutherland, R. (2011). Understanding teacher enquiry. Research in Mathematics Education, 13(1), 85. Retrieved from https://www.bsrlm.org.uk/IPs/ip30-2/BSRLM-IP-30-2-06.pdf

Khan, S. (2012). The one world schoolhouse: Education reimagined ( $1^{\text {st }}$ ed). New York, NY: Twelve.

Kim, M. (2012). Guiding framework and principles for technology integration: What are the key questions? In Polly, D., Mims, C., \& Persichitte, K. A. (Eds.) Developing technology-rich teacher education programs: Key issues (pp. 45-56) Hershey, Pa.: IGI Global. doi: 10.4018/978-1-4666-0014-0.ch004

Kirschner, P., Sweller, J., \& Clark, R. E. (2006). Why minimal guidance during instruction does not work: An analysis of the failure of constructivist, discovery, problem-based, experiential, and inquiry-based teaching. Educational Psychologist, 41(2), 75-86.

Kliebard, H. M. (2004). The struggle for the American curriculum, 1893-1958 ( $3^{\text {rd }}$ ed.). New York, NY: Routledge.

Koehler, M. J., \& Mishra, P. (2009). What is technological pedagogical content knowledge? Contemporary Issues in Technology and Teacher Education (CITE), 9(1), 60-70.

Koh, J. H. L., Chai, C. S., \& Tsai, C. C. (2010). Examining the technological pedagogical content knowledge of Singapore pre-service teachers with a large-scale survey. Journal of Computer Assisted Learning, 26(6), 563-573.

Kopcha, T. J. (2012). Teachers' perceptions of the barriers to technology integration and practices with technology under situated professional development. Computers \& Education, 59, 1109-1121. doi:10.1016/j.compedu.2012.05.014 
Kozma, R. B. (1994). Will media influence learning? Reframing the debate. Educational Technology Research \& Development, 42(2), 7-19.

Krajcik, J., Blumenfeld, P., Marx, R., \& Soloway, E. (2000). Instructional, curricular, and technological supports for inquiry in science classrooms. In Minstell, J. \& Van Zee, E. (Eds.) Inquiry into inquiry: Science learning and teaching. Part 3: What issues arise with inquiry learning and teaching (pp. 283-315). Washington, D.C.: American Association for the Advancement of Science Press.

Lakkala, M., Lallimo, J., \& Hakkarainen, K. (2005). Teachers' pedagogical designs for technology-supported collective inquiry: A national case study. Computers \& Education, 45(3), 337-356.

Littleton, K., \& Kerawalla, L. (2012). Trajectories of inquiry learning. In Littleton, K., Scanlon, E., \& Sharples, M. (Eds.) Orchestrating Inquiry Learning (pp.31-47). New York: Routledge.

Littleton, K., Scanlon, E., \& Sharples, M. (Eds.). (2012). Orchestrating inquiry learning. New York: Routledge.

Lowther, D. L., \& Morrison, G. R. (1998). The NTeQ model: A framework for technology integration. Techtrends, 43(2), 33.

Lowther, D. L., \& Morrison, G. R. (2003). Integrating computers into the problemsolving process. New Directions for Teaching \& Learning, (95), 33.

Main, R. G., \& Lucas, E. F. (2004). Distance learning on a dime: The union of Clark and Kozma. Journal of Interactive Instruction Development, 16(3), 3-8.

Mak, J. (2014). Coding in the elementary school classroom. Learning and Leading with Technology, 42(2), 26. Retrieved from http://www.iste.org/learn/publications/learning-leading/l-l-march-april2014/learning-connections-coding-in-the-elementary-school-classroom

Marzano, R. J. (2010). When practice makes perfect...sense. Educational Leadership, 68(3), 81-83. Retrieved from http://www.ascd.org/publications/educationalleadership/nov10/vol68/num03/When-Practice-Makes-Perfect-\%E2\%80\%A6Sense.aspx

Marzano, R. J. (2011). Research base and validation studies on the Marzano evaluation model. Retrieved from www.MarzanoEvaluation.com

McLeod, S. (Producer). (2011). Shift happens v5-Iowa, did you know? [Video File]. Retrieved from http://www.youtube.com/watch?v=dMsNct4X_GU 
Mellon, C. A. (1999). Technology and the great pendulum of education. Journal of Research on Computing in Education, 32(1), 28.

Mishra, P., \& Koehler, M. J. (2006). Technological pedagogical content knowledge: A framework for teacher knowledge. Teachers College Record, 108(6), 1017-1054. doi: 10.1111/j.1467-9620.2006.00684.x

Morrison, G. R., \& Lowther, D. L. (2010). Integrating computer technology into the classroom: Skills for the $21^{\text {st }}$ century $\left(4^{\text {th }}\right.$ ed.). Boston, MA: Pearson Education, Inc.

National Center for Education Statistics (NCES). (2002) Technology integration. In Technology in schools: Suggestions, tools and guidelines for assessing technology in elementary and secondary education, 73-97. Washington, D.C.: U.S. Department of Education.

National Center for Education Statistics (NCES). (2012). Common core of data. Retrieved from http://nces.ed.gov/ccd/index.asp

National Educational Technology Plan (2010). Transforming American education: Learning powered by technology. Alexandria, VA: U.S. Department of Education, Office of Educational Technology. Retrieved from www.ed.gov/sites/default/files/netp2010.pdf

National Governors Association (NGA) and the Council of Chief State School Officers (CCSSO). (2010). Common core mission statement. Retrieved from http://www.corestandards.org/

New Media Consortium (NMC). (2013). NMC horizon report: 2013 K-12 edition. Retrieved from http://www.nmc.org/publications/2013-horizon-report-k12

New Media Consortium. (2013). NMC horizon report: 2013 K-12 edition. Retrieved from http://www.nmc.org/publications/2014-horizon-report-k12

Newmann, F. M., Bryk, A. S., \& Nagaoka, J. (2001). Authentic intellectual work and standardized tests: Conflict or coexistence. Chicago: Consortium on Chicago School Research.

Niederhauser, D. S. (2013). Learning from technology or learning with technology. In M. P. Clough, J.K., Olson, \& D. S. Niederhauser (Eds.), The Nature of Technology, (pp. 249-267). SensePublishers. doi:10.1007/978-94-6209-269-3_14

Niederhauser, D. S., \& Lindstrom, D. L. (2006). Addressing the NETS for students through constructivist technology use in K-12 classrooms. Journal of Educational Computing Research, 34(1), 91-128. 
Ottenbreit-Leftwich, A. T., Glazewski, K. D., Newby, T. J., \& Ertmer, P. A. (2010). Teacher value beliefs associated with using technology: addressing professional and student needs. Computers \& Education, 55(3), 1321-1335.

Ozel, S., Yetkiner, Z., \& Capraro, R. M. (2008). Technology in K-12 mathematics classrooms. School Science and Mathematics, 108(2), 80. doi: 10.1111/j.19498594.2008.tb17807.x

Papert, S. (1993). The children's machine: Rethinking school in the age of the computer. New York: Basic Books.

Partnership for $21^{\text {st }}$ Century Skills. (2002). Learning for the $21^{\text {st }}$ century: A report and mile guide for $21^{\text {st }}$ century skills. Retrieved from http://www.p21.org/storage/documents/P21_Report.pdf

Partnership for $21^{\text {st }}$ Century Skills. (2011). $21^{\text {st }}$ Century Skills. Retrieved from http://www.p21.org/overview/skills-framework.

Pea, R., Milrad, M., Maldonado, H., Vogel, B., Kurti, A., \& Spikol, D. (2012). Learning and technological designs for mobile science inquiry collaboratories. In Littleton, K., Scanlon, E., \& Sharples, M. (Eds.), Orchestrating inquiry learning (pp.105127). New York: Routledge.

Penuel, W. R., \& Gallagher, L. P. (2009). Preparing teachers to design instruction for deep understanding in middle school earth science. Journal of Learning Sciences, 18(4), 461-508. doi: 10.1080/10508400903191904

Prensky, M. (2001). Digital natives, digital immigrants. On the Horizon, 9(5), 1-6. doi:10.1108/10748120110424816

Puentedura, R. R. (2013). SAMR. Hippasus. Retrieved from https://hippasus.com/rrpweblog

Roblyer, M. D. (2006). Integrating educational technology into teaching $\left(4^{\text {th }}\right.$ ed.). New Jersey: Pearson Education, Inc.

Saavedra, A., \& Opfer, V. D. (2012). Learning $21^{\text {st }}$ century skills requires $21^{\text {st }}$ century teaching. Phi Delta Kappan, 94(2), 8-13. Retrieved from http://www.kappanmagazine.org

Sanchez, A. X. (2011). Obstacles to integrating technology into the middle school curricula. (Ed.D., Walden University). ProQuest Dissertations and Theses. 
Sappey, J., \& Relf, S. (2010). Digital technology education and its impact on traditional academic roles and practice. Journal of University Teaching and Learning Practice, 7(1), 1-19.

Savery, J. R. (2006). Overview of problem-based learning: Definitions and distinctions. Interdisciplinary Journal of Problem-based Learning, 1(1).

Scanlon, E. (2012). Open educational resources in support of science learning: Tools for inquiry and observation. Distance Education, 33(2), 221-236.

Scanlon, Anastopoulou, \& Kerawalla. (2012). Inquiry learning reconsidered: Contexts, representations and challenges. In Littleton, K., Scanlon, E., \& Sharples, M. (Eds.), Orchestrating inquiry learning (pp.7-30). New York: Routledge.

Schank, R. (2011). Teaching minds: How cognitive science can save our schools. New York, NY: Teachers College Press.

Schümmer, T., \& Lukosch, S. (2007). Patterns for computer-mediated interaction. Hoboken, NJ: John Wiley \& Sons.

Schutt, R. K. (2009). Survey research. In Investigating the social world: The process and practice of research. (6 $6^{\text {th }}$ Ed.). (pp. 269-273). Washington, D.C.: Pine Forge Press.

Southwest Educational Development Laboratory (SEDL). (2013). Measuring implementation in schools: Stages of concern questionnaire. Permissions granted. Austin, TX: Southwest Educational Development Laboratory.

Sharples, M., \& Anastopoulou, S. (2012). Designing orchestration for inquiry learning. In Littleton, K., Scanlon, E., \& Sharples, M. (Eds.), Orchestrating inquiry learning (pp.69-85). New York: Routledge.

Shortell, J. (2010). Indexes and scales. Retrieved from http://survey.courseserve.info

Statistisches Bundesamt Deutschland. (2011). Zensus 2011. Retrieved from https://www.destatis.de.

Stewart, C., \& Schifter, C. (2010). Teaching and learning with technology: Beyond constructivism. New York, NY: Routledge.

Sutherland, R., Eagle, S., \& Joubert, M. (2012). A vision and strategy for technology enhanced learning: Report from the STELLAR network of excellence. Bristol, UK: STELLAR. Retrieved from www.stellarnet.eu 
Sutherland, R., \& Joubert, M. (2009). D1.1: The stellar vision and strategy statement. Referenced in Littleton, K., Scanlon, E., \& Sharples, M. (Eds.), Orchestrating inquiry learning. New York: Routledge.

Sutton, S. R. (2011). The preservice technology training experiences of novice teachers. Journal of Digital Learning in Teacher Education, 28(1), 39-47. Retrieved from http://files.eric.ed.gov/fulltext/EJ951442.pdf

Taylor, R. P. (1980). The computer in school: Tutor, tool, tutee. New York: Teachers College Press. Retrieved from: http://www.citejournal.org/vol3/iss2/seminal/article1.cfm

Taylor, R. P. (2003). Reflections on the computer in the school. Contemporary Issues in Technology and Teacher Education, 3(2), 253-274.

Tondeur, J., Kershaw, L. H., Vanderlinde, R., \& van Braak, J. (2013). Getting inside the black box of technology integration in education: Teachers' stimulated recall of classroom observations. Australasian Journal of Educational Technology, 29(3), 434-449.

University of Cambridge. (1997). International bachelorette: Primary years program.

U.S. Department of Commerce (2010). United States census. Retrieved from http://factfinder2.census.gov/ United States Census Bureau: Washington, D.C.

U.S. Department of Education (USDE): Office of Educational Technology. (2010). Transforming American education: National education technology plan executive summary. Alexandria, VA: Education Publications Center.

van Joolngen, W. R., de Jong, T., Lazonder, A. W., Savelsbergh, E. R., \& Manlove, S. (2005). Co-Lab: Research and development of an online learning environment for collaborative scientific discovery learning. Computers in Human Behavior, 21, 671-688.

Viilo, M., Seitamaa-Hakkarainen, P., \& Hakkarainen, K. (2012). Infrastructures for technology-supported collective inquiry learning. In K. Littleton, K., Scanlon, E., $\&$ Sharples, M. (Eds.), Orchestrating inquiry learning (pp.128-145). New York: Routledge.

Voogt, J., Fisser, P., Roblin, N. P., Tondeur, J., van Braak, J. (2012). Technological pedagogical content knowledge - a review of the literature. Journal of Computer Assisted Learning, 29(2), 109-121. doi: 10.1111/j.1365-2729.2012.00487.x 
Wang, F., \& Hannafin, M. J. (2005). Design-based research and technology-enhanced learning environments. Educational Technology Research and Development, (4), 5.

Weinberger, A., Stegmann, K., \& Fischer, F. (2007). Knowledge convergence in collaborative learning: Concepts and assessment. Learning and Instruction, 17(4), $416-426$

Wentworth, N., \& Monroe, E. E. (2011). Inquiry-based lessons that integrate technology: Their development and evaluation in elementary mathematics teacher education. Computers in the Schools, 28(4), 263-277.

White, B. Y. \& Frederiksen, J. R. (1998). Inquiry, modeling, and metacognition: Making science accessible to all students. Cognition and Instruction, 16(1), 3. Retrieved from http://www.jstor.org/stable/323366

Wiesen, N. (2014, January 7). 5 trends in education for 2014. [Web log]. Scientific Learning. Retrieved from http://www.scilearn.com/blog/5-trends-in-education2014.php

Young, J. R., Young, J. L., \& Hamilton, C. (2013). The use of confidence intervals as a meta-analytic lens to summarize the effects of teacher education technology courses on preservice teacher TPACK. Journal of Research on Technology in Education, 46(2):149-172. doi: 10.1080/15391523.2013.10782617 


\title{
APPENDIX A
}

\section{INSTRUMENT}

\author{
PART I \\ Stages of Concern Questionnaire \\ *Permissions Granted by SEDL (2013)i
}

The purpose of this questionnaire is to determine what people who are using or thinking about using various programs are concerned about at various times during the adoption process.

The items were developed from typical responses of school and college teachers who ranged from no knowledge at all about various programs to many years' experience using them. Therefore, many of the items on this questionnaire may appear to be of little relevance or irrelevant to you at this time. For the completely irrelevant items, please circle " 0 " on the scale. Other items will represent those concerns you do have, in varying degrees of intensity, and should be marked higher on the scale.

For example:

This statement is very true of me at this time.

This statement is somewhat true of me now.

$\begin{array}{llllllll}0 & 1 & 2 & 3 & 4 & 5 & 6 & 7 \\ 0 & 1 & 2 & 3 & 4 & 5 & 6 & 7 \\ 0 & 1 & 2 & 3 & 4 & 5 & 6 & 7 \\ 0 & 1 & 2 & 3 & 4 & 5 & 6 & 7\end{array}$

Please respond to the items in terms of your present concerns, or how you feel about your involvement with integrating technology into the classroom. We do not hold to any one definition of technology integration so please think of it in terms of your own perception of what it involves. Phrases such as "this approach" and "the new system" all refer to the same innovation. Remember to respond to each item in terms of your present concerns about your involvement or potential involvement with integrating technology into the classroom.

Thank you for taking time to complete this task.

\begin{tabular}{|c|c|c|c|c|c|c|}
\hline 0 & 1 & 2 & 3 & 4 & 6 & 7 \\
\hline Irrelevant & \multicolumn{2}{|c|}{ Not true of me now } & \multicolumn{2}{|c|}{ Somewhat true of me now } & \multicolumn{2}{|c|}{ Very true of me now } \\
\hline
\end{tabular}




\begin{tabular}{|c|c|c|c|c|c|c|c|c|}
\hline $\begin{array}{l}\text { 1. I am concerned about students' attitudes toward the } \\
\text { integration of technology. }\end{array}$ & 0 & 1 & 2 & 3 & 4 & 5 & & 7 \\
\hline $\begin{array}{l}2 \text {. I now know of some other approaches that might work } \\
\text { better. }\end{array}$ & 0 & 1 & 2 & 3 & 4 & 5 & & 7 \\
\hline 3. I am more concerned about another innovation. & 0 & 1 & 2 & 3 & 4 & 5 & 6 & 7 \\
\hline $\begin{array}{l}\text { 4. I am concerned about not having enough time } \\
\text { to organize myself each day. }\end{array}$ & 0 & 1 & 2 & 3 & 4 & 5 & 6 & 7 \\
\hline
\end{tabular}

5. I would like to help other faculty in their use of integrating technology.

$\begin{array}{llllllll}0 & 1 & 2 & 3 & 4 & 5 & 6 & 7\end{array}$

\begin{tabular}{ll|llllllll} 
6. I have a very limited knowledge of technology integration. & 0 & 1 & 2 & 3 & 4 & 5 & 6 & 7
\end{tabular}

7. I would like to know the effect of reorganization on my professional status.

$\begin{array}{llllllll}0 & 1 & 2 & 3 & 4 & 5 & 6 & 7\end{array}$

8. I am concerned about conflict between my interests and my responsibilities.

$\begin{array}{llllllll}0 & 1 & 2 & 3 & 4 & 5 & 6 & 7\end{array}$

9. I am concerned about revising my use of technology integration.

10. I would like to develop working relationships with both our faculty and outside faculty using technology

$\begin{array}{llllllll}0 & 1 & 2 & 3 & 4 & 5 & 6 & 7\end{array}$ integration.

11. I am concerned about how the integrating technology affects students.

$\begin{array}{llllllll}0 & 1 & 2 & 3 & 4 & 5 & 6 & 7\end{array}$

12. I am not concerned about the integration of technology at this time.

13. I would like to know who will make the decisions in the new system.

$\begin{array}{llllllll}0 & 1 & 2 & 3 & 4 & 5 & 6 & 7\end{array}$

14. I would like to discuss the possibility of integrating technology.

15. I would like to know what resources are available if we decide to adopt technology integration. 


\begin{tabular}{|c|c|c|c|c|c|c|c|c|}
\hline $\begin{array}{l}\text { 16. I am concerned about my inability to manage all } \\
\text { that technology integration requires. }\end{array}$ & 0 & 1 & 2 & 3 & 4 & 5 & 6 & 7 \\
\hline $\begin{array}{l}\text { 17. I would like to know how my teaching or } \\
\text { administration is supposed to change. }\end{array}$ & 0 & 1 & 2 & 3 & 4 & 5 & 6 & 7 \\
\hline $\begin{array}{l}\text { 18. I would like to familiarize other departments or } \\
\text { persons with the progress of this new approach. }\end{array}$ & 0 & 1 & 2 & 3 & 4 & 5 & 6 & 7 \\
\hline 19. I am concerned about evaluating my impact on students. & 0 & 1 & 2 & 3 & 4 & 5 & 6 & 7 \\
\hline 20. I would like to revise the technology integration approach. & 0 & 1 & 2 & 3 & 4 & 5 & 6 & 7 \\
\hline $\begin{array}{lll}0 & 1 & 2\end{array}$ & & & & 6 & & 7 & & \\
\hline Somewhat true of me now & & Very & true & e of & f me $n$ & now & & \\
\hline & & Circle & One & $\mathrm{Nu}$ & imber & For E & Each 1 & Item \\
\hline $\begin{array}{l}\text { 21. I am preoccupied with things other than technology } \\
\text { integration. }\end{array}$ & 0 & 1 & 2 & 3 & 34 & 5 & 6 & \\
\hline $\begin{array}{l}\text { 22. I would like to modify our use of integrating technology based } \\
\text { on the } \\
\text { experiences of our students. }\end{array}$ & 0 & 1 & 2 & 3 & 34 & 5 & 6 & 7 \\
\hline 23. I spend little time thinking about integrating technology. & 0 & 1 & 2 & 3 & 34 & 5 & 6 & 7 \\
\hline $\begin{array}{l}\text { 24. I would like to excite my students about } \\
\text { their part in this approach. }\end{array}$ & 0 & 1 & 2 & 3 & 34 & 5 & 6 & 7 \\
\hline 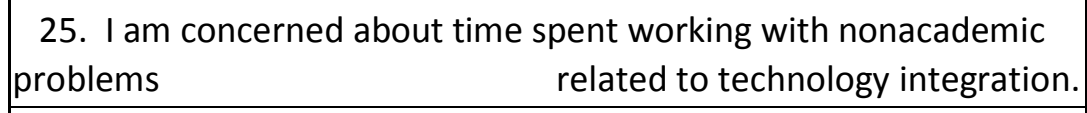 & 0 & 1 & 2 & 3 & 34 & 5 & 6 & 7 \\
\hline $\begin{array}{l}\text { 26. I would like to know what the use of } \\
\text { integrating technology will require in the } \\
\text { immediate future. }\end{array}$ & 0 & 1 & 2 & 3 & $\begin{array}{l}34 \\
\end{array}$ & 5 & 6 & 7 \\
\hline $\begin{array}{l}\text { 27. I would like to coordinate my efforts with others to } \\
\text { maximize technology integrations' effects. }\end{array}$ & 0 & 1 & 2 & 3 & 34 & 5 & 6 & 7 \\
\hline $\begin{array}{l}\text { 28. I would like to have more information on time and energy } \\
\text { commitments required by integrating technology. }\end{array}$ & 0 & 1 & 2 & 3 & $\begin{array}{l}34 \\
\end{array}$ & 5 & 6 & 7 \\
\hline $\begin{array}{l}\text { 29. I would like to know what other faculty are doing } \\
\text { in this area. }\end{array}$ & 0 & 1 & 2 & 3 & 34 & 5 & 6 & 7 \\
\hline $\begin{array}{l}\text { 30. Currently, other priorities prevent me from focusing my } \\
\text { attention on integrating technology. }\end{array}$ & & 1 & 2 & 3 & 34 & 5 & 6 & 7 \\
\hline
\end{tabular}




\begin{tabular}{|c|c|c|c|c|c|c|c|}
\hline $\begin{array}{l}\text { 31. I would like to determine how to supplement, enhance, or } \\
\text { replace the integration of technology. }\end{array}$ & 0 & 1 & 2 & 3 & 4 & 56 & 6 \\
\hline $\begin{array}{l}\text { 32. I would like to use feedback from students to } \\
\text { change the program. }\end{array}$ & 0 & 1 & 2 & 3 & 4 & 56 & \\
\hline $\begin{array}{l}\text { 33. I would like to know how my role will change when } \\
\text { I am integrating technology. }\end{array}$ & 0 & 1 & 2 & 3 & 4 & 56 & \\
\hline $\begin{array}{l}\text { 34. Coordination of tasks and people is taking too much of my } \\
\text { time. }\end{array}$ & 0 & 1 & 2 & 3 & 4 & 56 & \\
\hline $\begin{array}{l}\text { 35. I would like to know how integrating technology is } \\
\text { better than what we have now. }\end{array}$ & 0 & 1 & 2 & 3 & 4 & 56 & 6 \\
\hline
\end{tabular}

Please complete the following:

1. How long have you been involved with technology integration, not counting this year?

Never _ 1 year _ 2 years _ 3 years _ 4 years $\_5$ or

2. In your use of technology integration, do you consider yourself to be a: non-user _ novice _ _ intermediate _ old hand _ _ past user

3. Have you received formal training regarding integrating technology (workshops, courses)? Yes _ No

4. Are you currently in the first or second year of use of some major innovation or program other than integrating technology?

Yes _ No N

If yes, please describe briefly:

Continue to Part 2.

SEDL (2013). Measuring implementation in schools: Stages of concern questionnaire. 
Permissions granted. Austin, TX: Southwest Educational Development Laboratory. 
Evaluating the Use of Technology within Pedagogy

Directions: Please answer the following questions regarding your current practice of technology use within the classroom. You may elect to answer as few or as many of these questions as you wish to participate in the survey.

For the purpose of this survey: the use of the word, technology, includes all computers, laptops, tablets, and mobile devices.

Section A: Demographics Indicate one response per question.

1. Please indicate your current professional setting:

a. International school

b. Illinois public school

2. Years of Teaching Experience:
$\square 1-5$
$\square$ 6-10
$\square$ 11-15
$\square 16-20$
$\square 21-25$
$\square 26-30 \quad \square 30+$

3. Age group of the students you currently teach:
a. Elementary (Student Ages 3-11)
b. Middle School (Student Ages 12-14)
c. High School (Students Ages 15-18)

4. Is your classroom self-contained or non-self-contained?

a. Self-contained (i.e., you teach multiple subjects to the same group of students)

b. Non-self-contained (i.e., you teach the same subject to multiple classes of students)

Section B: Pedagogical Practices

Indicate the single best response to each statement below, according to the scale. Measure your use from "almost never" to use in "almost all lessons".

\begin{tabular}{|c|c|c|c|c|}
\hline $\begin{array}{l}\text { 5. About how often do the students in your classroom take part in } \\
\text { the following activities? } \\
\text { In my classroom students: }\end{array}$ & 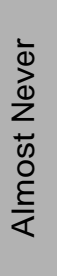 & 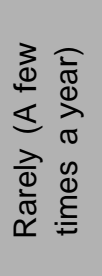 & 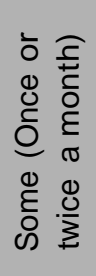 & 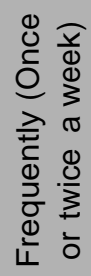 \\
\hline a. Generate their own ideas and questions to learn & O & $\mathrm{O}$ & $\mathrm{O}$ & O \\
\hline b. Solve problems within small groups & $\mathrm{O}$ & $\mathrm{O}$ & $\mathrm{O}$ & $\mathrm{O}$ \\
\hline c. Ask questions about what they observe & $\mathrm{O}$ & $\mathrm{O}$ & $\mathrm{O}$ & $\mathrm{O}$ \\
\hline d. Plan investigations to answer questions & $\mathrm{O}$ & $\mathrm{O}$ & $\mathrm{O}$ & $\mathrm{O}$ \\
\hline e. Conduct research & $\mathrm{O}$ & $\mathrm{O}$ & $\mathrm{O}$ & $\mathrm{O}$ \\
\hline f. Record data within their research & $\mathrm{O}$ & $\mathrm{O}$ & $\mathrm{O}$ & $\mathrm{O}$ \\
\hline g. Use the data they collected to develop explanations & $\mathrm{O}$ & $\mathrm{O}$ & O & $\mathrm{O}$ \\
\hline h. Report their research findings & $\mathrm{O}$ & $\mathrm{O}$ & $\mathrm{O}$ & $\mathrm{O}$ \\
\hline i. Reflect on their learning process & $\mathrm{O}$ & $\mathrm{O}$ & $\mathrm{O}$ & $\mathrm{O}$ \\
\hline
\end{tabular}




\begin{tabular}{|c|c|c|c|c|}
\hline $\begin{array}{l}\text { 6. About how often do you use technology within the following } \\
\text { instructional strategies in your classroom: }\end{array}$ & 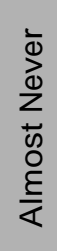 & 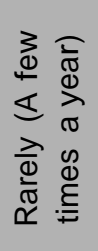 & 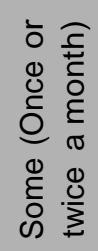 & 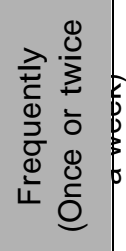 \\
\hline a. Exploration Learning & 0 & 0 & 0 & 0 \\
\hline b. Simulations & 0 & 0 & 0 & 0 \\
\hline c. Case Studies & 0 & 0 & $\mathrm{O}$ & O \\
\hline d. Experimentation & $\mathrm{O}$ & 0 & $\mathrm{O}$ & 0 \\
\hline e. Problem-solving & 0 & O & $\mathrm{O}$ & O \\
\hline
\end{tabular}

\begin{tabular}{|c|c|c|c|c|c|}
\hline $\begin{array}{l}\text { 7. How often do students in your class (es) use technology } \\
\text { to do the following? } \\
\text { Mark "Not Applicable" only if this use does not apply to your } \\
\text { subject area: }\end{array}$ & 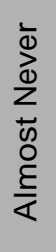 & 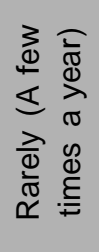 & 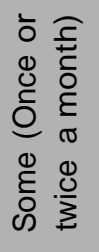 & 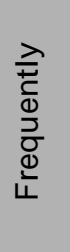 & $\begin{array}{l}\frac{0}{0} \\
\frac{0}{0} \\
\frac{0}{0} \\
\frac{0}{2} \\
\frac{1}{2} \\
\frac{0}{2}\end{array}$ \\
\hline $\begin{array}{l}\text { a. Communicate with experts using technology, for example, } \\
\text { (over email, synchronous communication, like Skype, or } \\
\text { through discussion boards) to collaborate }\end{array}$ & O & O & O & $\mathrm{O}$ & $\mathrm{O}$ \\
\hline $\begin{array}{l}\text { b. Communicate with peers in or beyond your school using } \\
\text { technology, for example, (over email, synchronous } \\
\text { communication, like Skype, or through discussion boards) to } \\
\text { collaborate }\end{array}$ & $\mathrm{O}$ & O & $\mathrm{O}$ & $\mathrm{O}$ & $\mathrm{O}$ \\
\hline $\begin{array}{l}\text { c. Solve real-world problems (i.e., involving situations, } \\
\text { issues, and tasks that people actually tackle in the outside } \\
\text { world) }\end{array}$ & $\mathrm{O}$ & $\mathrm{O}$ & $\mathrm{O}$ & $\mathrm{O}$ & $\mathrm{O}$ \\
\hline $\begin{array}{l}\text { d. Produce multi-media, Web, or presentation products to } \\
\text { communicate the results or report learning }\end{array}$ & $\mathrm{O}$ & $\mathrm{O}$ & $\mathrm{O}$ & $\mathrm{O}$ & $\mathrm{O}$ \\
\hline e. Conduct online research to compare sources & $\mathrm{O}$ & $\mathrm{O}$ & $\mathrm{O}$ & $\mathrm{O}$ & $\mathrm{O}$ \\
\hline $\begin{array}{l}\text { f. Visually represent or investigate concepts (e.g., through } \\
\text { concept mapping, graphing, reading charts) to evaluate } \\
\text { information gathered }\end{array}$ & $\mathrm{O}$ & $\mathrm{O}$ & $\mathrm{O}$ & $\mathrm{O}$ & $\mathrm{O}$ \\
\hline
\end{tabular}

8. Has your use of technology created a more student-centered learning environment within your classroom?
a. Yes
b. No

9. My students use technology as a:
a. tool to support learning. For example; to collect information for learning, to put together a product of learning
b. tutor to assist instruction. For example; to reinforce or practice learning, using the computer to teach the child
c. tutee as the format for learning. For example; the student teaches the computer to produce what knowledge they have synthesized


10. Who determines the technology tool that is utilized?

a. Determined by the teacher according to the need of the lesson

b. Determine by the students' decision to use the technology

11. Prior to the use of technology within a lesson, I:

a. Teach students objectives of the lessons

b. Have students learn using a different media

c. Provide students with a list of questions they will need to use technology to answer

d. Have students generate a list of search terms

e. Have students develop questions that they will need to use technology to answer

12. During the use of technology within a lesson, the students' primary use of software is:

a. Production (word, publisher etc.)

b. Research (search engines)

c. Communication (e-mail, blogs, wikis)

d. Problem-solving (gaming, simulations)

e. Educational (drill and practice, tutorials)

Directions: For items 13-16 please indicate what you are mostlikely to do in your current practice.

13. Instead of writing a report by hand, I am most likely having my students

a. Typing their report

b. Typing their report and using spell check, grammar check and electronic dictionary functions

c. Using a program like Google Docs to use a commenting service or the review function of a Word document for instance, to collaborate and share feedback on a given task

d. Using the chat function of Google Docs, share and collaborate with individuals around the world, synthesizing two or more documents

14. To have students produce a presentation (PowerPoint, SMARTNotebook, Keynote or Prezi), I am most likely having my students

a. Creating presentation slides

b. Creating a presentation with embedded video

c. Creating a presentation with manipulative components, such as a Notebook document with a matching activity.

d. Creating a presentation with the capabilities of interaction between the presenter and audience with response tools

15. Within the research process, I am most likely having my students use technology by

a. Using the internet to read informational websites

b. Using the internet to read informational websites and then use referenced websites to continue research

c. Using a web-quest to simulate the process of research gathering

d. Using a data sharing system such as GLOBE to collect and share data collected in research

16. To learn mathematic concepts, I am most likely having my students

a. Using a website that practices math facts with students

b. Using a website that practices math facts with students and adjusts problem set according to student performance

c. Using interactive manipulatives to represent a math concept (such as using a model, image, or representation)

d. Having students create an audio-visual video modeling a math strategy to post on the internet for sharing

Learning Point Associates (2008). Inquiry-based instruction in lowa: A report on the implementation of every learner inquires in year 2. Retrieved from: http://www.air.org/files/2646 ELI Year 2 Report final-ed2.pdf ii SETDA/Metiri Suite (2004). PETI evaluating educational technology effectiveness. Retrieved from: http://www.setda.org/web/guest/PETItools 


\section{APPENDIX B}

\section{SCRIPT FOR SCHOOL ADMINISTRATION: REQUEST TO CONTACT TEACHERS}

Use: For use with personal contact (face-to-face), synchronous telecommunication contact (via Skype), or e-mail contact for recruitment.

Researcher says: Hello, [name of administration contact] my name is Ashley Mayor, and I am a graduate student at Illinois State University. I am contacting you today to request permission to contact teachers at your school to volunteer as participants in a research study I am conducting focused on technology integration within teaching and learning.

I am interested in finding out what your educators have to say about technology integration. I would like your permission to contact your teaching staff via email or in person to invite them to participate in the survey. I would be asking your teachers to complete a questionnaire which would be provided to them via email or hard-copy format according to their preference. I have included a copy of the survey for you to consider my request.

The teachers from your staff who elect to participate in the study will not be asked to provide any identifiable information. Teachers have the right to abstain from answering a question, clarify an answer, or stop taking the questionnaire, if they so wish. They be asked for informed consent and are encouraged to ask any questions they may have of the study.

The questionnaire will inquire about teacher perceptions and experiences with the integration of technology and will take no more than 20 minutes of their time.

Please sign below to indicate that I have your permission to contact your teaching staff to request their participation in my study. Your signature indicates consent that I have permission to contact your teachers via email or in person to request their participation. Their participation is their own will and consent. At the conclusion of the research, I will communicate research findings with you via email.

Thank you for your time and consideration of my proposal. Ashley Mayor

I

the teaching staff at (Name) grant permission to Ashley Mayor to contact participation in her research study. Signature: Date: (School Name) to request 


\section{APPENDIX C \\ PARTICIPANT RECRUITMENT}

\section{PART I: Script for Participant Recruitment}

Use: For use with personal contact (face-to-face), synchronous telecommunication contact (via Skype), or e-mail contact for recruitment.

Researcher says: Hello, [name of potential participant] my name is Ashley Mayor, and I am a graduate student at Illinois State University. I am contacting you today to invite you to volunteer as a participant in a research study to ask your perception of technology integration within teaching and learning.

I am interested in finding out what you have to say about technology integration as a respected colleague. You qualify for participation as a technology-using educator in a K12 setting. I have received permission to contact you through your school administration. I am privileged to have the opportunity to work with you as you help me with my thesis research towards completion of my degree.

As a volunteer, you will be asked to complete a questionnaire conducted in three parts. The questionnaire will be provided via email or via hard-copy format, according to your preference. The data you submit will be stored electronically once returned. Your information will be kept confidential and private; no aspects of your identity will be revealed. If at any time while completing the questionnaire you wish to abstain from answering a question, clarify an answer, or stop taking the questionnaire, you may do so. You are encouraged to ask questions regarding the study at any time.

The questionnaire will inquire about your perceptions and experiences with the integration of technology in your teaching practice and will take no more than 20 minutes of your time. The goal of this study is to determine how teacher practitioners perceive the technology integration process and find means to do so. Your participation in this study will contribute to understandings of how technology integration can best be implemented. 
If you are willing to participate in my study, next I will provide you with the consent form and questionnaire. At the conclusion of the research, I will communicate research findings with you via email.

Thank you for your time and consideration of my proposal. Ashley Mayor

\section{Part II: Participant Consent Form}

Dear Practitioner:

I am a graduate student under the direction of Dr. Thomas Lucey, in the College of Education, School of Teaching and Learning at Illinois State University. I am conducting a research study to determine teacher perceptions on the integration of technology across varied educational settings. I am requesting your participation, which will involve the completion of a two part questionnaire and should take no more than 20 minutes of your time to complete. The questionnaire will be provided via email or via hard-copy format, according to your preference. The data you submit will be stored electronically once returned. The questionnaire will inquire about your perceptions and experiences with the integration of technology in your teaching practice.

Your participation in this study is voluntary. If at any time while completing the questionnaire you wish to abstain from answering a question, clarify an answer, or stop taking the questionnaire, you may do so. You are encouraged to ask questions regarding the study at any time. If you choose not to participate or to withdraw from the study at any time, there will be no penalty. Your responses are confidential and any information that might allow someone to identify you will not be disclosed.

Illinois State University has a strong commitment to ensure that all participants are treated in the highest ethical manner. I can assure you that there are no risks involved with participation beyond those of everyday life. The goal of this study is to determine how teacher practitioners perceive the technology integration process and find means to do so. Your participation in this study will contribute to understandings of how technology integration can best be implemented.

If you have any questions concerning the research study, please call me at (708) 204-6750 or email me at acmayor@ilstu.edu, or Skype at acmayor86.

Sincerely,

Ashley Mayor

I consent to participating in the above study.

Signature

Date 
If you have any questions about your rights as a subject/participant in this research, or if you feel you have been placed at risk, you can contact the Research Ethics \& Compliance Office at Illinois State University at (309) 438-2529. 


\section{APPENDIX D}

\section{SEDL LICENSE AGREEMENT}

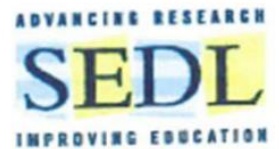

SEDL License Agreement

To:

Ashley Mayor (Licensee)

503 W. Jefferson St., Apt. 3

Morton, IL 61550

From: $\quad$ Nancy Reynolds

Information Associate

SEDL

Information Resource Center-Copyright Permissions

4700 Mueller Blvd.

Austin, TX 78723

Subject: License Agreement to reprint and distribute SEDL materials

Date: $\quad$ September 30, 2013

Thank you for your interest in using the Stages of Concern Questionnaire (SoCQ 075) published by SEDL in Measuring Implementation in Schools: The Stages of Concem Questionnaire written by Archie A. George, Gene E. Hall, and Suzanne M. Stiegelbauer in 2006, as Appendix A, pages 79-82; it is also A. George, Genetronic format as SEDL's Stages of Concern Questionnaire (SoCQ) Online available from available in electronic format as SEDL's Stages of Concern

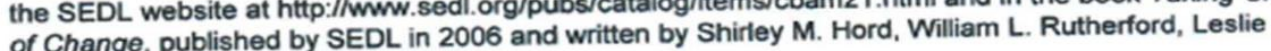
Huling, and Gene E. Hall, on pages 48-49.

SoCQ 075 will be referred to as the "work" in this permission agreement. SEDL is pleased to grant permission for use of the work by the Licensee to focus on technology integration within elementary schools in a research study at Illinois State University in Morton, IL. The following are the terms, conditions, and limitations governing this limited permission to reproduce the work:

1. All reprinting and distribution activities shall be solely in the media in which the work has been made available for your use, i.e., copy made from a print copy or SEDL's SoCQ Online version, and shall be used for educational, non-profit use only. Precise compliance with the following terms and conditions shall be required for any permitted reproduction of the work described above.

2. No adaptations, deletions, or changes are allowed with the exceptions of substituting the words "the innovation" with a word or phrase that participants will recognize, and adding questions to identify demographic indicators of participants before or after the instrument, but the wording and order of items cannot be changed in the work. No additional derivative work based on or incorporating the work will be created without the prior written consent of SEDL. 
SEDL License Agreement, p. 2

3. This permission is non-exclusive, non-transferable, and limited to the one-time use specified herein. This permission is granted solely for the period September 30, 2013, through December 31,2014 , inclusive. SEDL expressly reserves all rights in this material.

4. You must give appropriate credit: "Reprinted by Ashley Mayor with permission from SEDL," or attribute SEDL as appropriate to the professional style guidelines you are following. All reproductions of the material used by you shall also bear the following copyright notice on each page of use: "Copyright @ $\odot 2006$, SEDL."

5. An exact copy of any printed reproduction of the work you produce shall be promptly provided to SEDL. All copies of the work produced by you which are not distributed or used shall be destroyed or sent to SEDL, save and except a maximum of three archival copies you are permitted to keep in permanent records of the activity you conducted.

6. This License Agreement to reproduce the work is limited to the terms hereof and is personal to the person and entity to whom it has been granted; and it may not be assigned, given, or transferred to any other person or entity.

7. SEDL is not charging the Licensee a copyright fee to use the work.

I'm e-mailing you a PDF of this agreement. Please print and sign one copy below, indicating that you understand and agree to comply with the above terms, conditions and limitations, and send the original back to me. If you wish to keep a copy with original signatures, please also print, sign, and return a second copy and, after I receive and sign it, I'Il return it with both of our signatures to you.

Thank you, again, for your interest in using the Stages of Concern Questionnaire. If you have any questions about SEDL's License Agreement, please contact me at 800-476-6861, ext. 6548 or $512-391-6548$, or by e-mail at nancy.reynolds@sedl.org.

Sincerely,

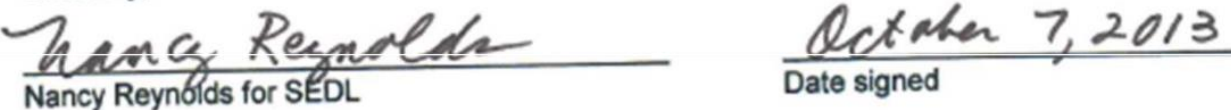

Agreed and accepted:

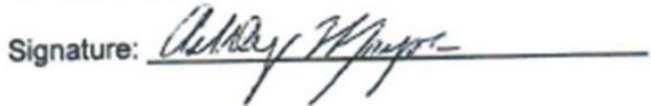

September 30,2013

Date signed

Printed Name:

ASHLEY MAYOR

SEDL (2013). Measuring implementation in schools: Stages of concern questionnaire. Permissions granted. Austin, TX: Southwest Educational Development Laboratory. 